\title{
Progress in bioremediation of pesticide residues in the environment
}

\author{
Balendu Shekher Giri ${ }^{1,2^{*}}$, Sachin Geed ${ }^{1^{*}}$, Kumar Vikrant ${ }^{3}$, Sang Soo Lee ${ }^{4}$, Ki-Hyun Kim $^{3^{\dagger}}$, \\ Suresh Kumar Kailasa ${ }^{5}$, Meththika Vithanage ${ }^{6}$, Preeti Chaturvedi ${ }^{2}$, Birendra Nath Rai ${ }^{1}$, \\ Ram Sharan Singh ${ }^{1^{\dagger}}$
}

${ }^{1}$ Department of Chemical Engineering and Technology, Indian Institute of Technology (Banaras Hindu University), Varanasi 221005, India ${ }^{2}$ Aquatic Toxicology Laboratory, Environmental Toxicology Group, Council of Scientific and Industrial Research-Indian Institute of Toxicology Research (CSIR-IITR), Lucknow 226001, Uttar Pradesh, India

${ }^{3}$ Department of Civil and Environmental Engineering, Hanyang University, Seoul 04763, Republic of Korea

${ }^{4}$ Department of Environmental Engineering, Yonsei University, Wonju 26493, Republic of Korea

${ }^{5}$ Department of Applied Chemistry, S.V. National Institute of Technology, Surat 395007, Gujarat, India

${ }^{6}$ Ecosphere Resilience Research Center, Faculty of Applied Sciences, University of Sri Jayewardenepura, Nugegoda 10250, Sri Lanka

*These authors contributed equally to this work.

\section{ABSTRACT}

The increasing use of various pesticides (e.g., organophosphate, organochlorine, carbamates, and pyrethroid) has helped to improve agricultural productivity by minimizing the potential crop losses associated with insect attacks. Owing to their highly recalcitrant nature, most pesticides and their residues often accumulate in the environment to exert deleterious effects on human health and various ecosystems. Among a variety of remediation options, biological approaches have attracted a widespread attention for the treatment of pesticide in soil/water systems due to their environmentally benign nature. In this regard, this review article was organized to highlight the recent advancements in the application of various bioremediation approaches for the degradation/removal of pesticides from soil/water matrixes along with the catabolic capacity of microorganisms. Our discussions were expanded further to emphasize identification of specific bacterial communities/strains, such as Bacillus sp. and Pseudomonas sp. This review is expected to provide an overview of the modern biotechnological methodologies along with the associated merits and hurdles for the effective abatement of pesticides.

Keywords: Bioreactors, Degradation factors, Microbial degradation, Organophosphate pesticides, Organochlorine insecticides, Soil remediation

\section{Introduction}

Pesticides produced as insecticides, herbicides, fungicides, and in many other forms have been used for agricultural or horticultural purposes [1]. This revolutionary development in agriculture technologies enhanced the crop yield while reducing the risk of crop loss or quality deterioration [2]. However, these substances are commonly dispersed contaminants due to their toxicity, persistence, and degradation by-products.

Pesticides have become essential features in modern agriculture for economical pest management and better crop production accompanied by the rapid growth of the global population, e.g., 1.1\% increase of pesticide use in 2016 over the previous year [3]. The use of pesticides and associated environmental contaminants are expected to become worse in the foreseeable future. Approximately 2.4 million metric tons of pesticides were used worldwide (as of 2014) to control various insects, weeds, fungi, and other unwanted organisms in agricultural and urban environments [4]. Due to excessive application, pesticide residues were reported to remain in the environment longer than 10 years and are detected at a level of $\mu \mathrm{gL}^{-1}$ in water resources or $\mu \mathrm{g} \mathrm{kg}^{-1}$ in soils [5]. Human exposure to pesticides at a relatively high concentrationcan occur through soils and drinking water, thereby threatening human health and potentially causing fertility disorders due to their high carcinogenicity and neurotoxicity [6, 7].

Due to the detection of pesticides and residues in water sources,
This is an Open Access article distributed under the terms of the Creative Commons Attribution Non-Commercial License (http://creativecommons.org/licenses/by-nc/3.0/) which permits unrestricted non-commercial use, distribution, and reproduction in any medium, provided the original work is properly cited.

Copyright (C) 2021 Korean Society of Environmental Engineers
Received August 05, 2020 Accepted November 05, 2020

${ }^{\dagger}$ Corresponding author

Email: kkim61@hanyang.ac.kr, rssingh.che@itbhu.ac.in Tel: +822-2220-2325

ORCID: 0000-0001-5167-9154 


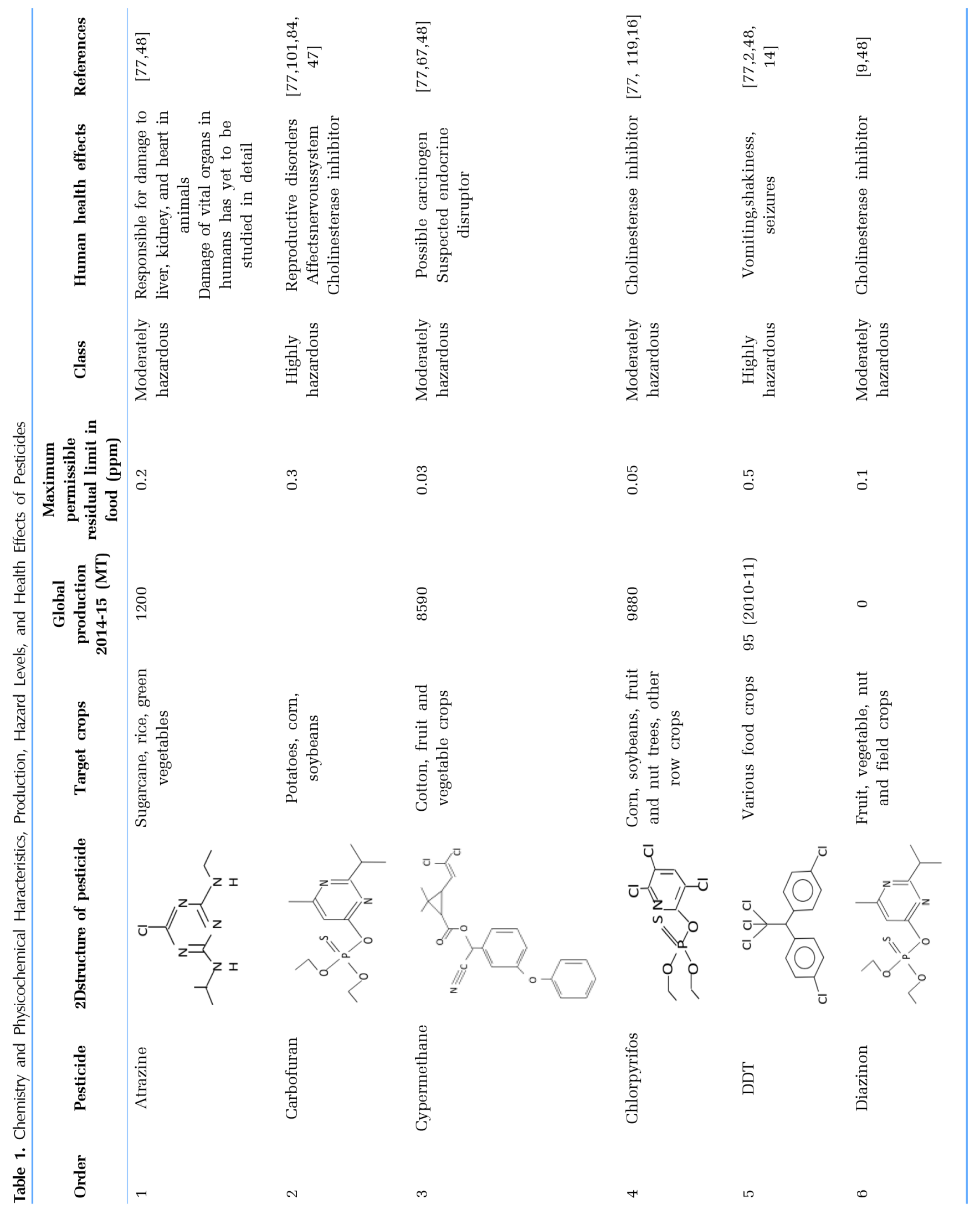




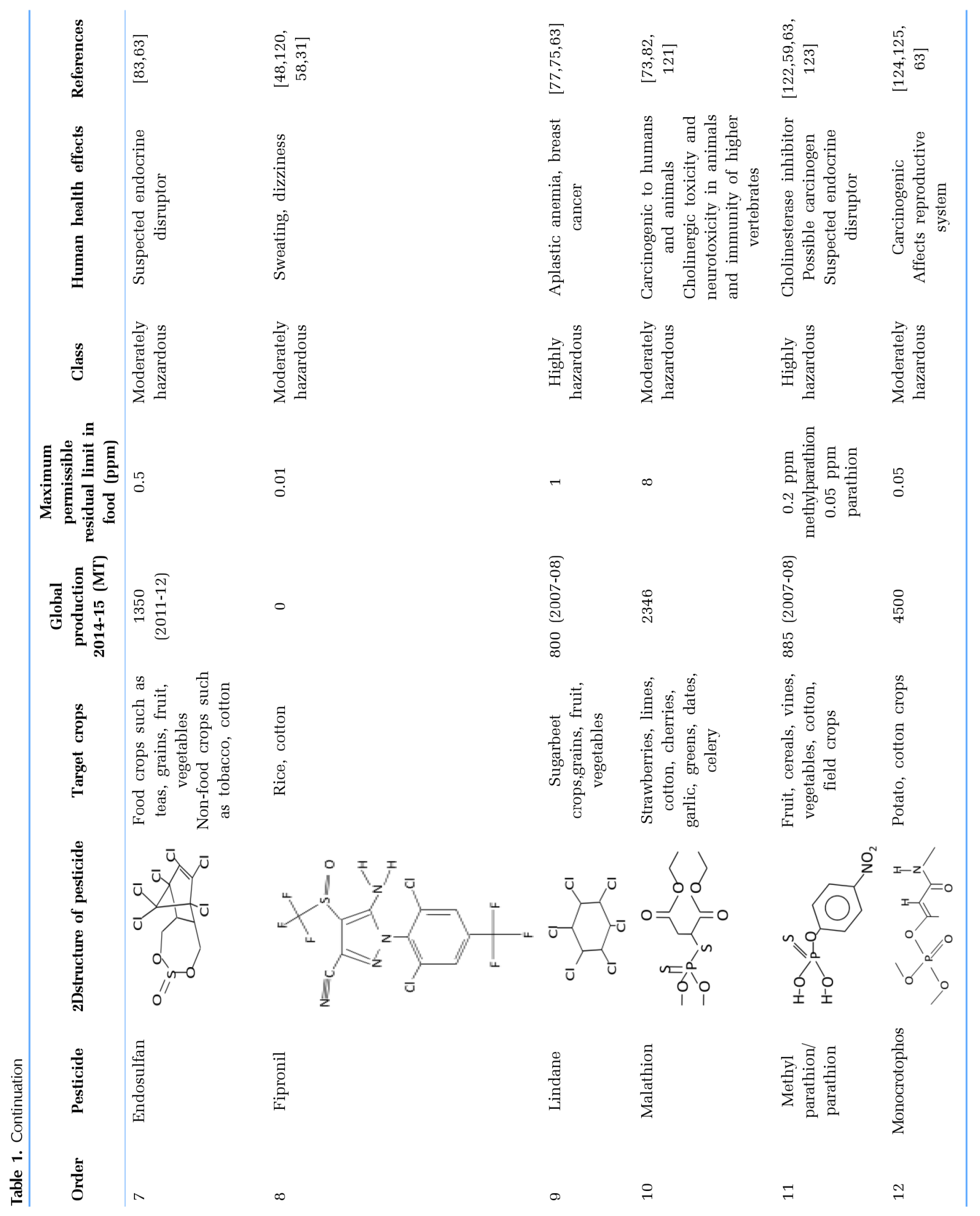




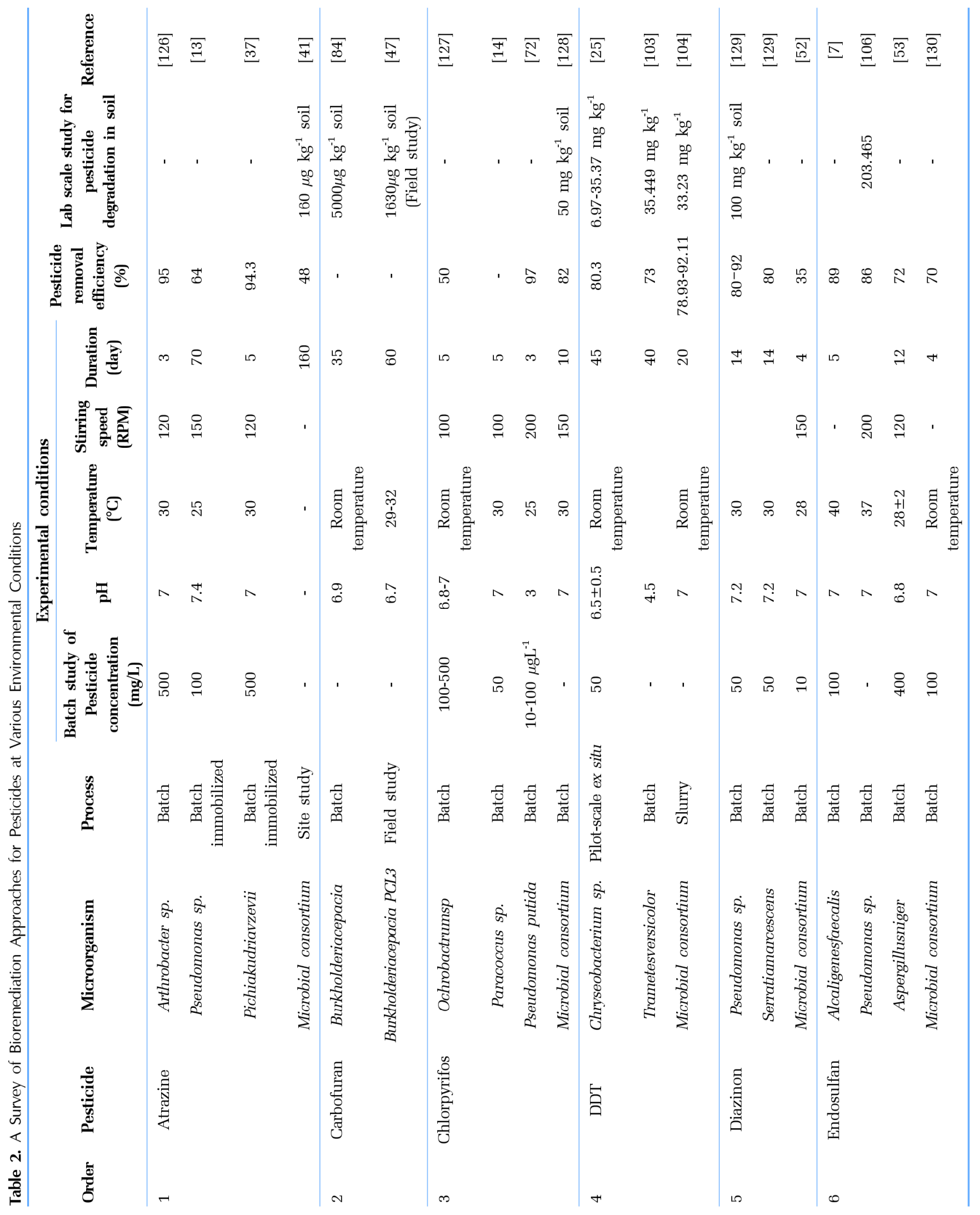




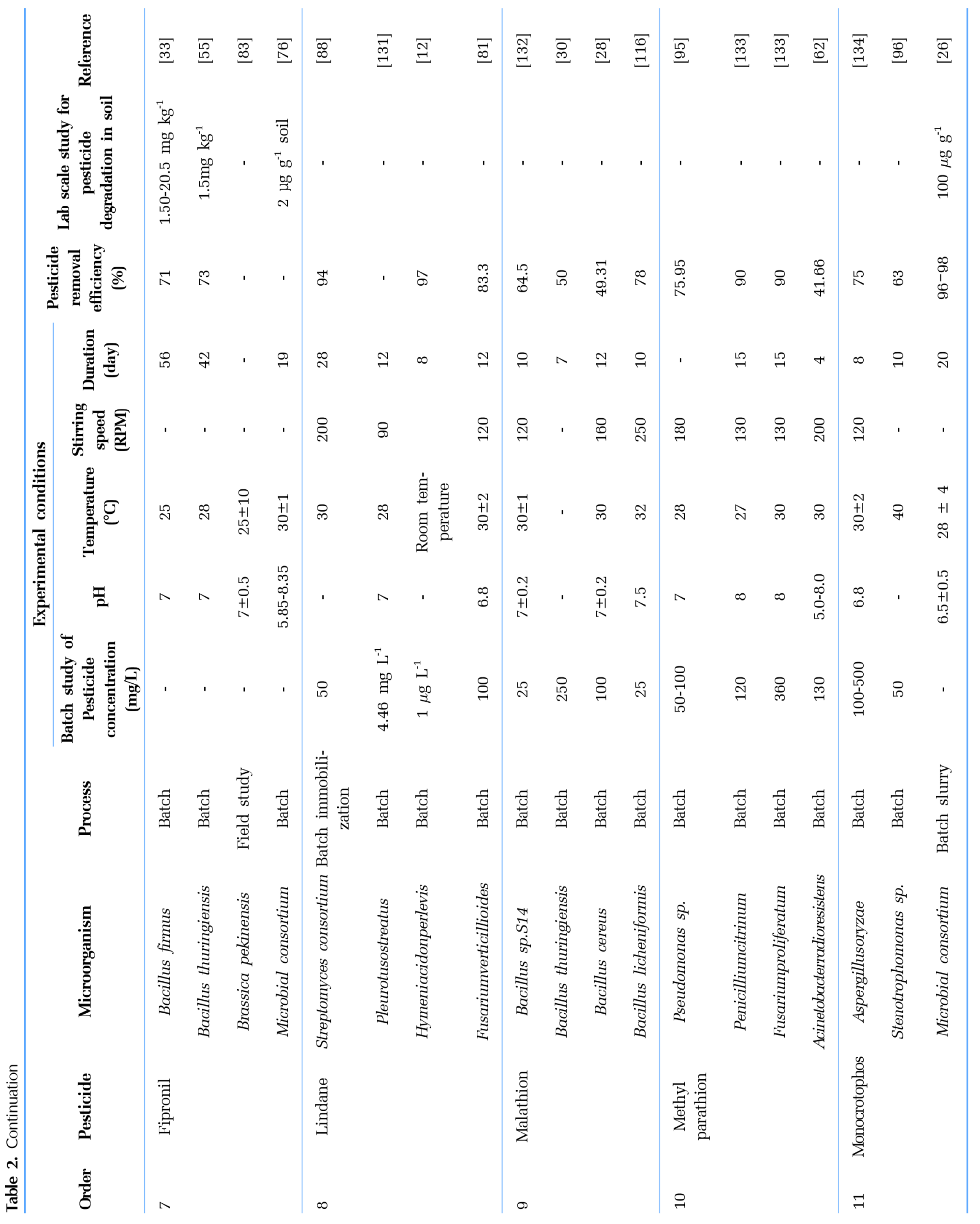


many studies have focused on developing physicochemical technologies for wastewater treatment to remove such residues [8-10]. However, conventional techniques suffer from critical disadvantages, such as equipment complexity, high operating costs, excessive sludge generation, and toxic wastes as byproducts. To solve these issues, many studies suggested the use of biological methods for treating a wide range of pesticides, due to their cost-effective, highly selective, and environmentally benign nature [11-14]. However, the use of biological approaches is also limited by requirements such as a need to be compatible with the environment, uncomplicated access of the microbial population to the pesticide molecules, and procurement of suitable pesticide-degrading microorganisms [15]. Despite decades of research, the scale-up of pesticide bioremediation approaches from lab-scale into field trials has been very challenging.

The term "bioremediation" is the method of pollutant biodegradation in nature based on the metabolic capacity of microbes to breakdown various organic compounds like pesticides [16, 17]. In pesticide bioremediation, microbes with specifically/genetically enhanced functionality utilize pesticide molecules for their metabolic activity through conversion into environmentally benign products/metabolites [18]. A brief summary of the literature on the general properties of pesticides and bioremediation is provided in Tables 1 and 2, respectively.

This review focuses on the impact of various factors (e.g., pesticide structure, concentration, $\mathrm{pH}$, temperature, and moisture) on the biodegradation of pesticides and the major techniques that are available for pesticide assays in soils. The latest bioremediation approaches on the degradation of organophosphate, organochlorine, carbamates, and pyrethroid pesticides in soil and water are also discussed. In this review, authors sought to highlight the advantages and drawbacks of the present bioremediation approaches for pesticides through an in-depth analysis and comparison with conventional physicochemical methods. The results of this effort will help us to enhance our knowledge of this highly challenging field

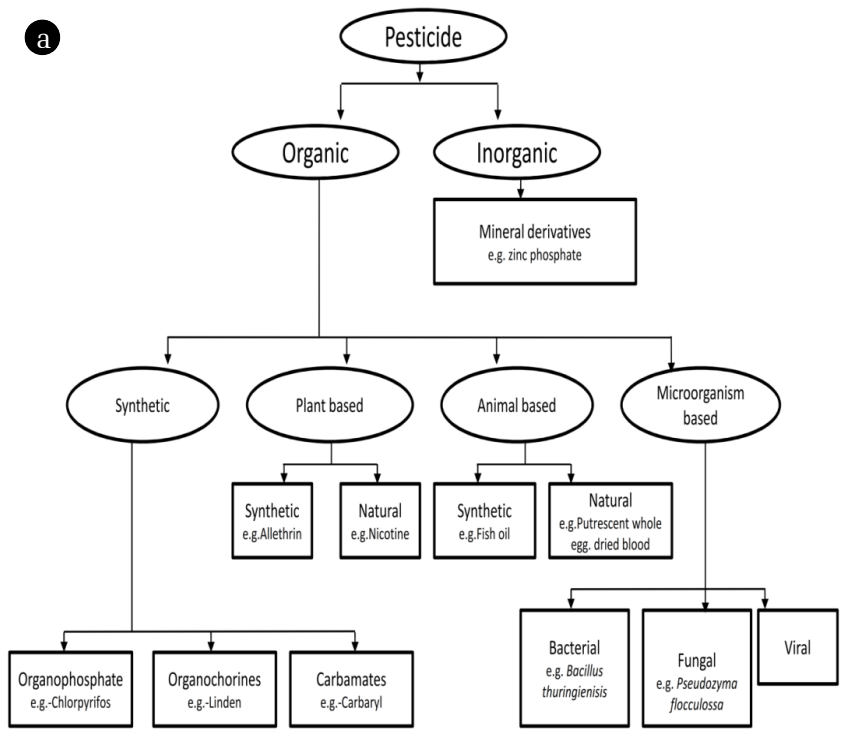

of research. Furthermore, we highlight the use of microorganisms to understand the catabolic ability of the target soil and to demonstrate the benefit of combining traditional bioremediation techniques with molecular techniques.

\section{Chemistry of Pesticides}

Pesticides are classified by their nature, feedstock, and pest control capability. Depending on the pesticide's origin, it is classified as a chemical pesticide or a bio-pesticide. Chemical pesticides are further divided into four main types, namely organophosphates, organochlorines, carbamates, and pyrethroids. Bio-pesticides are derived naturally from living organisms, including bacteria, fungi, and plants. They can commonly be classified into three major groups, microbial, biochemical, and plant-incorporated protectants. Further, the classification of pesticides can also be made based on their pest-controlling capabilities: insecticides (for insects), nematicides (for nematodes), fungicides (for fungi), herbicides/weedicides (for weeds), algaecides (for algae), and rodenticides (for rats) (Figure 1 and 1S; Pesticides can be applied directly to specific plant parts or above-ground to be transported into the soil and to soil-based organisms. Depending on the application method, a fraction of the pesticide, ranging from 30.0-90.0\%, infiltrate directly into the soil system [21, 22]. The impacts of various pesticides on specific soil organisms, soil food chains, and biological soil functions can vary depending on the type or amount of pesticides, soil environment, and soil biota. The impacts can be expanded to the health of the entire soil community with noticeable damage to various soil functions [23]. Pesticides are degraded by both biotic and abiotic processes into intermediate or secondary products that may have even worse toxicity than the parent pesticide. Biodegradation of pesticides/herbicides is also greatly influenced by soil conditions (e.g., temperature, moisture, organic matter content, and $\mathrm{pH}$ ) along with microbial characteristics and pesticide solubility [24].

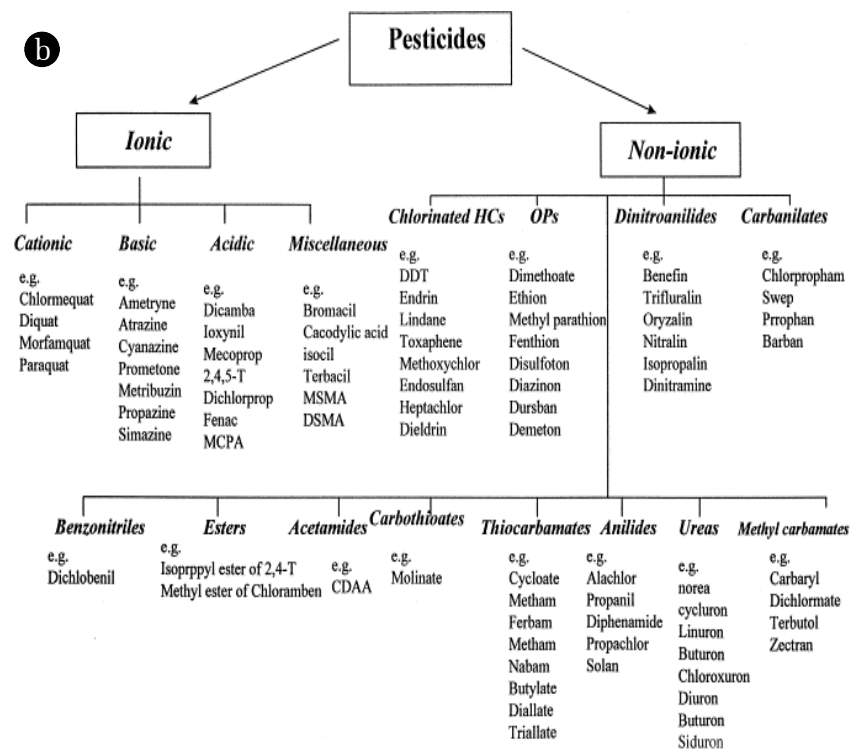

Fig. 1. Classification of several types of pesticides and examples: (a) on the basis of inorganic and organic pesticides, (b) on the basis of ionic forms. 


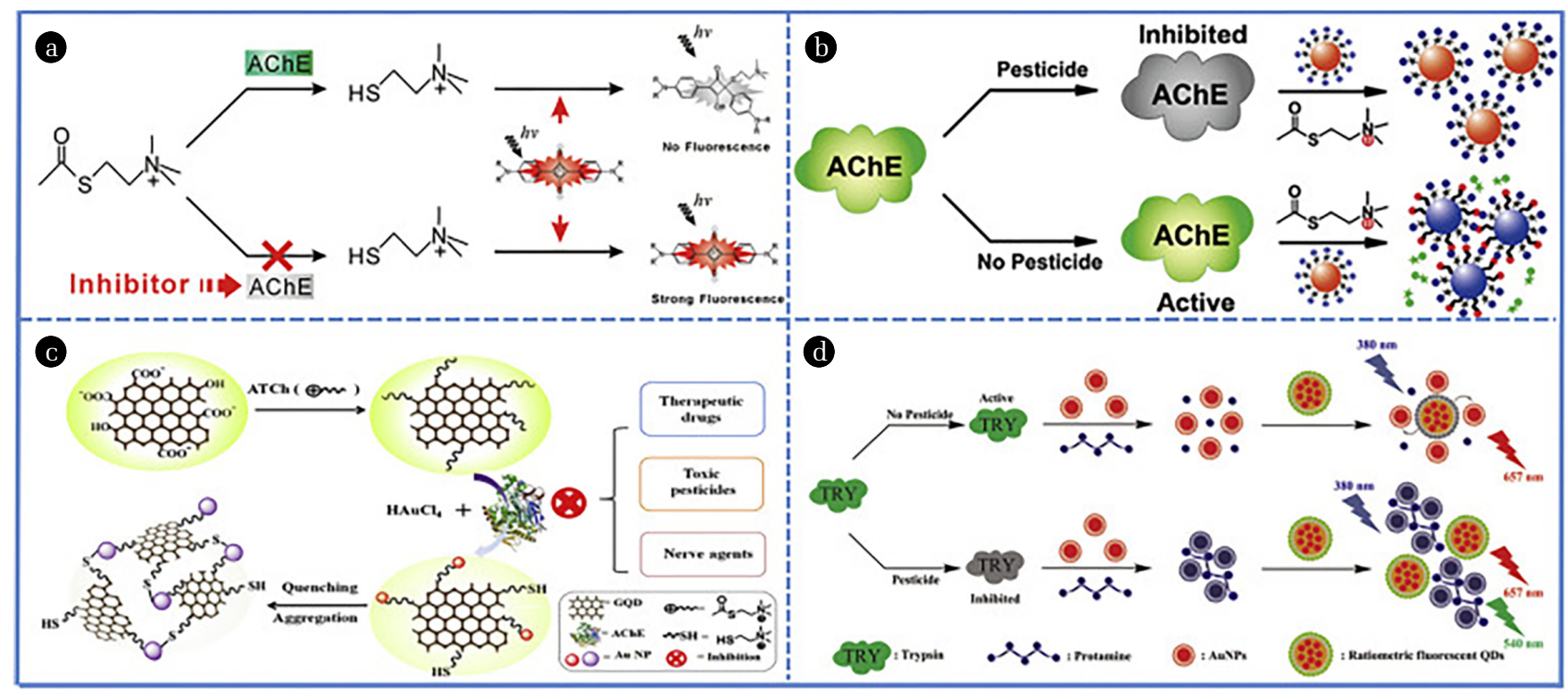

Fig. 2. Optical sensing strategies for pesticides: (a) description of the signal-on fluorometric strategy for cetylcholinesterase inhibitors; (b) design of the dual-readout (colorimetric and fluorometric) assay for pesticides; (c) schematic illustration of GQD-ATC/AuNPsfluorometric detection of AChE and its inhibitors; (d) illustration of the fluorescent detection of OPs through the inner-filter effect of gold nanoparticles on RF-QDs.

As the world population increases, the consumption of pesticides has dramatically increased and accelerated to maximize agricultural productivity and to satisfy food demand. However, its effects on long-term sustainability, soil degradation, water nitrification, natural resource management, and climate change are still unclear, as shown in Fig. 2 [25, 26]. The residual levels of pesticides in foods have been monitored and regulated based on the maximum residue level (MRL), as established by phyto-sanitary studies. In 2007, approximately $2.3 \times 10^{6}$ tons of pesticides were used worldwide, and their sales in 2014 reached 52 billion USD [27]. In the European Union, more than 800 pesticides have been authorized, although fewer than 300 pesticides are used in practice [28-30]. As of 2016, China was the largest consumer of agricultural pesticides $\left(1.81 \times 10^{6}\right.$ ton $\left.\mathrm{y}^{-1}\right)$, followed by the US $\left(3.86 \times 10^{5}\right.$ ton $\left.\mathrm{y}^{-1}\right)$, Argentina $\left(2.65 \times 10^{5}\right.$ ton $\left.\mathrm{y}^{-1}\right)$, Japan $\left(5.2 \times 10^{4}\right.$ ton $\left.\mathrm{y}^{-1}\right)$, and India $\left(4.0 \times 10^{4}\right.$ ton $\mathrm{y}^{-1}$ ). The potential crop losses by pests without any pesticides varied from $\sim 50.0 \%$ (e.g., barley) to $\sim 80.0 \%$ (e.g., sugar, cotton, and beet) [31]. Actual losses with proper pesticides are estimated to be $26.0-30.0 \%$ for soybeans, sugar, barley, beets, cotton, and wheat, while they are $35.0 \%$ for maize, $39.0 \%$ for potatoes, and $40.0 \%$ for rice [31].

\section{Physicochemical Methods as Pesticide Treatments}

\subsection{Extraction}

Extract is a commonly used lab-scale method to remove pesticides from soils and water systems; this technique includes solid-phase extraction (SPE) and liquid-liquid extraction (LLE) [32]. For the LLE technique, chlorinated solvents (e.g., tetrachloroethane, chlor- obenzene, and carbon tetrachloride) or $n$-hexane are widely used to determine the toxicity of pesticides. Supercritical extraction $\left(\mathrm{SC}-\mathrm{CO}_{2}\right)$ was used to treat organophosphate pesticides. In $\mathrm{SC}-\mathrm{CO}_{2}$, pesticide removal depends on the solubility of the pesticide, the critical temperature, and pressure of supercritical $\mathrm{CO}_{2}$ [29]. Unfortunately, there is no breakdown of pesticides into less toxic compounds. This technique requires a high operation cost to maintain the critical temperature and pressure [33]. An average removal of $90.0 \%$ was reported for organophosphate pesticides in a very short time (e.g., $20 \mathrm{~min}$ ) at a temperature of $90.0^{\circ} \mathrm{C}$ and a pressure of $235 \mathrm{~atm}$ (Table 3). The major disadvantages of this process are high cost and limited operational conditions (i.e., no decomposition of pesticides below the SC- $\mathrm{CO}_{2}$ temperature). The nature of pollutants such as pesticides is also crucial to determine the suitability of separation methods. This may be due to the fact that the selection of a suitable solvent is very crucial to remove the pollutants such as pesticides. Pesticides in diverse forms (e.g., suspensible concentrates, granules, controlled-release formulations, and baites) require special attention and treatment. Comparisons of diverse approaches have been made for the extraction of pesticides using liquid-liquid extraction (LLE), solid-phase extraction (SPE), and solid-phase micro-extraction (SPME) against enriched river water samples. These authors have reported that the SPE is better than LLE because of 10 times less soil sample requirements which contained the pesticides or other organic pollutants [29-33]. In general, compared to liquid-liquid extraction, solid phase extraction can be exercised with a small amount of samples.

\subsection{Adsorption}

Adsorption is a method to remove pesticides in which a certain adsorbate is transferred selectively to the surface of an insoluble immobile phase, i.e., the adsorbent. Adsorption is classified by 


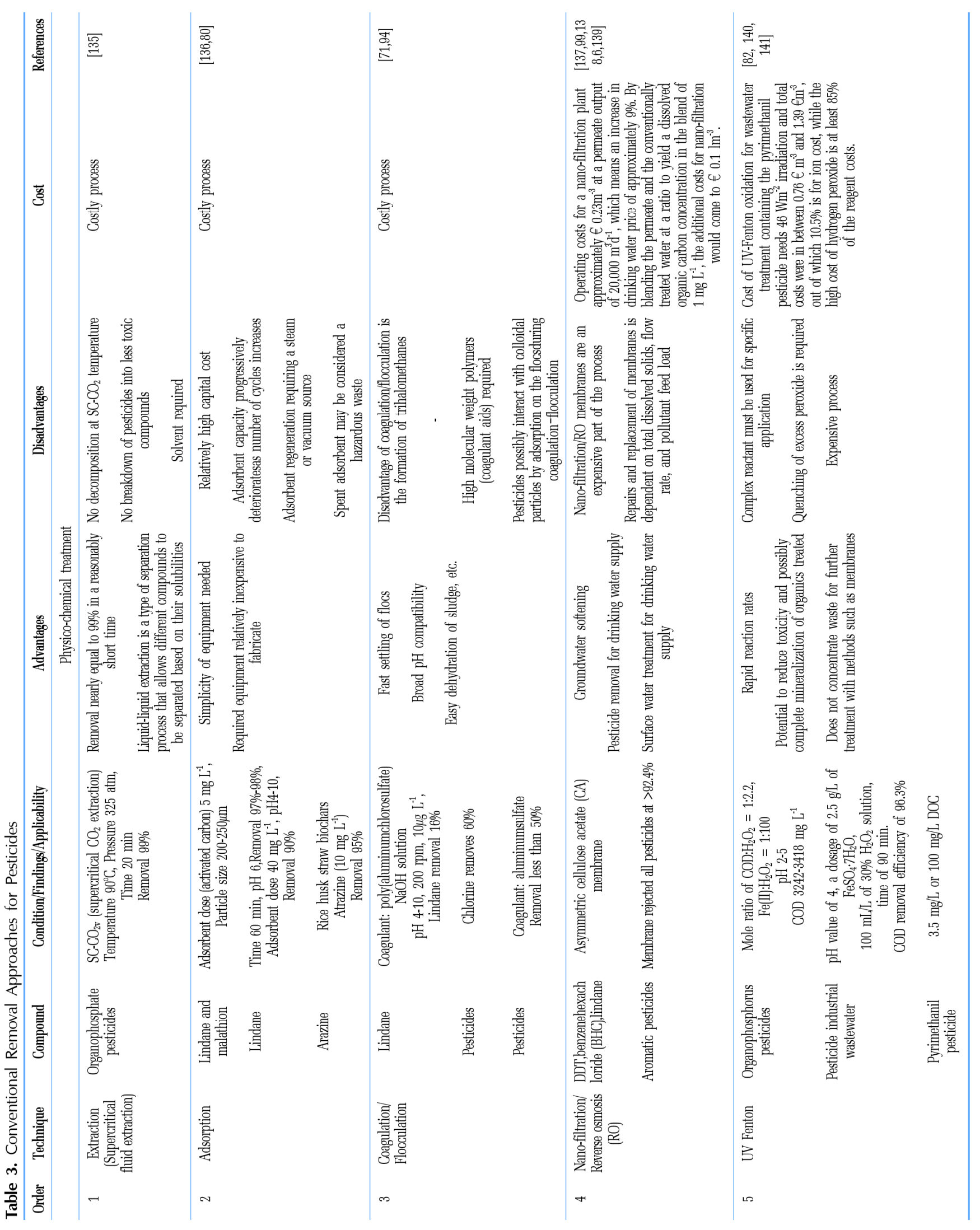


the type of bonding between the adsorbed species and the adsorbent, i.e., physisorption (by weak van der Waals forces) or chemisorptions (by covalent bonding). Pesticide residues need to be treated physically or chemically to avoid water contamination [34]. Residual removal of pesticides by conventional methods is being applied in wastewater treatment facilities through chemical oxidation, sedimentation, flocculation, coagulation, and filtration (using traditional sorbents). Nonetheless, they may not be effective enough [35]. In contrast, the adsorption method using activated carbon appears to be the most effective because it can remove a wide range of organic compounds from water. Activated carbon is one of the most extensively used adsorbent materials because of its porous in nature and high surface area (Table 3). Similarly, a study found that rice straw biochar showed similarities to activated carbon and removed $95.0 \%$ of atrazine at $10 \mathrm{mg} \mathrm{L}^{-1}$ [10]. Another researcher reported that the adsorption doses of lindane and Malathion were around $5.0 \mathrm{mg} \mathrm{L}^{-1}$ and 200-250 $\mu \mathrm{m}$, respectively, when using activated carbon as an adsorbent [36]. Removal efficiency of $95.0 \%$ was also observed for biochar derived from rice husk for the sorptive removal of atrazine (at an initial concentration of $10 \mathrm{mg} \mathrm{L}^{-1}$. The disadvantages of adsorption-based methods are the relatively high capital cost and progressive deterioration in the sorption capacity as the number of cycle increases. Also, the conventional adsorbents often lack target specific functional sites on their surfaces to lower the adsorption capacities of pesticide. In this regard, future research should be directed to properly assess the performance of novel sorbents (e.g., metal-organic frameworks) towards the removal of pesticides. The surface of conventional adsorbents can also be suitably modified to enhance pesticide adsorption capacity.

\subsection{Coagulation/flocculation}

Pesticide levels in drinking water have significantly increased, and thishasbecome a major concern [37].The European Parliament \& Council (EPC, 2000) [38] set a concentration limit of $0.1 \mathrm{mg}$ $\mathrm{L}^{-1}$ for pesticides in drinking and groundwater for a single pesticide and $0.5 \mathrm{mg} \mathrm{L}^{-1}$ for the total content of all pesticides [39, 40]. Removal efficiencies of common pesticides methyl parathion and chlorpyrifos were $79.0 \%$ and $82.0 \%$, respectively, using commercial coagulants alum and ferric chloride [41]. The coagulant dose, initial $\mathrm{pH}$, and type of coagulant were considered to estimate the removal of chlorpyrifos and methyl parathion.

In a wastewater treatment plant, coagulation/flocculation is a general step in the physicochemical process. Coagulation is a method used to remove humic substances, heavy metals, phenols, and cyanides from industrial alkaline wastewater, landfill leachate, and drinking water [42]. The mechanisms involved in pesticide pollutant removal include a combination of entrapment, adsorption, charge neutralization, and interactions with the aggregation of insoluble precipitates/polymers, as shown in Table 3[42].

\subsection{Nano-filtration (NF) and Reverse Osmosis (RO) Membranes}

Various membrane technologies were developed in the mid-1980s, followed by progress in related factors or variables, such as the capacity to reject salt, resistance to chemicals, and pressure requirements. These developments have led to the fabrication of nano-filtration (NF) membranes, and subsequently, and the pro- duction of ultra-low-pressure reverse osmosis (RO) membranes [43]. There are differences between the technologies mentioned above like nano-filtration and reverse osmosis membranes in terms of extraction yield, simplicity of operation, investment cost, operation time, safety, and degree of automation. All of them have comparative advantages relative to the traditional solvent extraction such as extraction, distillation method, pressing, and sublimation according to the extraction principle. Regardless of the technology selected for the extraction, subsequent steps are needed for separation, purification, and final concentration. The next section will introduce conventional and non-conventional separation methodologies.

Nanofiltration is a pressure-driven membrane process used for removing solutes with molecular weight in the range of 200-1,000 gmol $^{-1}$, typically from aqueous streams [170]. The operating pressures of reverse osmosis and nanofiltration are $100-300$ and 50 - 150 psi [170]. A myriad of commercial NF/RO membranes have been investigated for the effective removal of a large number of pesticides (e.g., atrazine, diazinon, and dichlorovos) from various water matrixes [44]. The selection of a suitable membrane plays a pivotal role in the removal of pesticides from drinking water. The removal of pesticides by membranes is primarily governed by the physicochemical properties of the pesticide (e.g., molecular weight and size, acid disassociation constant, and hydrophilicity/hydrophobicity. In general, the sieving effect (size exclusion principal) is the prime mechanism for the membrane-based treatment of pesticides [45-47] estimated the operating cost for aNF plant to be $€ 0.23 \mathrm{~m}^{-3}$ at a permeate output rate of 20,000 $\mathrm{m}^{3} \mathrm{~d}^{-1}$, which implied an approximately $9.0 \%$ hike in the price of potable water. Water was treated by mixing with a NF permeate.

Membranes with an average pore size smaller than pesticide molecules may retain the target compounds depending on the physicochemical affinity of the pesticide molecules towards the membrane. Membranes are commercially used to remove pesticides from raw water for producing potable water [46] due to their easy operation. However, membrane fouling decreases the efficiency of pesticide removal from water [44].

\subsection{Ultraviolet (UV)-Fenton}

Ultraviolet (UV)-Fenton oxidation is an accelerated photoreaction in the presence of a catalyst. In the UV-Fenton reaction, UV light is absorbed by an adsorbate substrate and used for the removal of a wide range of pesticides. Hydroxyl radical-based advanced oxidation processes (AOPs) have been developed to remove pesticides, including atrazine, and hydroxyl radicals can be generated by UV photolysis of hydrogen peroxide [48]. This process is much faster than bioremediation in treating pesticides. However, it is costly and requires very high energy consumption and strong oxidizing chemical doses, which are the major drawbacks for AOPs [49]. The Fenton reaction has widely been applied in the treatment of wastewater pesticides [50]. Many organophosphate pesticides can be removed by UV-Fenton techniques. The advantages and disadvantages of various operation conditions are shown in Table 3. UV-Fenton oxidation is also a very common method for treating wastewater containing the pesticide pyrimethanil. For example, $100 \mathrm{mg} \mathrm{L}^{-1}$ DOC needs $46 \mathrm{Wm}^{-2}$ irradiation along with a total cost of $€ 0.76-1.39 \mathrm{~m}^{-3}$ (10.5\% of this is for ion cost). 


\section{Bioremediation}

Although a wide array of research and development has been undertaken in the area of pesticide abatement form soils, the transfer of these technologies to the field is very challenging. In the subsequent sections, authors highlight the benefits of combining conventional bioremediation methods with the molecular techniques reported. Bioremediation is a greener route to remove many pollutants from the environment [14, 51]. Microbe-assisted degradation of pesticides is governed by the access of pesticide molecules to a pesticide-consuming microbial population and the activity of this population [52]. Nature keeps the concentration of pesticides in soil in check through the consumption of toxic pesticide molecules by indigenous microbial populations, thus bringing benefits for both agriculture and ecology [21, 53, 54]. However, the natural biodegradation kinetics of pesticides is very slow because of their highly recalcitrant molecular structure. These pesticide molecules remain persistent in soil. As a result, microbiological investigations are essential for developing new and advanced biotechnological tools for the detoxification of pesticides by highly selective microbial species [22].

Bioremediation technology utilizes the natural biodegradation process of hazardous pollutants in its favor by significantly elevating the activity and development of these organisms to convert toxic compounds into environmentally benign products. Bacteria, fungi, or plants can be used to treat pesticides for various contaminated sites. These microbes play a crucial role in the breakdown of hazardous pesticide molecules. An estimate revealed that 1-g soil carries more than one hundred million bacteria (including 5,000-7,000 unique strains) and more than 10,000 colonies of fungi [55]. Natural attenuation (usage of indigenous microbial population) can be effectively utilized for the removal of toxic pollutants from the environment [56]. In recent decades, many researchers have focused on the application of in-situ biodegradation of hazardous compounds with naturally occurring microbial populations [54]. The strains of Acinetobacter johnsonii, Lysini bacillus, Bacillus sp., and Pseudomonas sp. have been isolated from contaminated soils and sludge generated from agricultural and industrial sites and used for degradation of pesticides [57]. Table 2 shows the degradation of pesticides using specific microorganisms.

The capability of fungal populations to convert a myriad of toxic compounds into environmentally benign species has attracted a great deal of scientific attention for bioremediation applications [58]. The uniqueness of fungi lies in the fact that they secrete diverse extracellular enzymes. Although several soil bacterial species aregenerally omnipresent in a wide array of moist soils, fungi display a higher removal tendency for pesticides, even in semi-arid and aridsoils. Highly recalcitrant pesticides such as the chlorinated triazine herbicide 2-chloro-4-ethylamine-6-isopropylamino-1,3,4triazine (atrazine) have been transformed by the white-rot fungi Phanerochaete chrysosporium and Pleurotus pulmonarius, yielding hydroxylated and $\mathrm{N}$-dealkylated metabolites [59].

The biodegradation of atrazine, malathion, and parathion was carried out in a two-stage integrated aerobic treatment plant (IATP) using Bacillus sp. (consortia) isolated from an agricultural field $[22,54]$. The influent stream containing these pesticides (initial chemical oxygen demand COD of $123 \mathrm{mg} \mathrm{L}^{-1}$ ) was fed to the first reactor which was fed to the second reactor. The maximum removal of pesticides in IATP was greater than 90\%. Further, these studies attempted the biodegradation of atrazine in synthetic wastewater by the isolated microbial Alcaligenes sp. S3 from an agricultural field in an alternating aerobic-anoxic lab-scale pilot plant [21]. Wastewater contaminated with atrazine at $200 \mathrm{mg} \mathrm{L}^{-1}$ and a COD value of $1,356 \mathrm{mg} \mathrm{L}^{-1}$ was treated across varying flow rates. Accordingly, 90.6\% removal of COD was obtained at a flow rate of $300 \mathrm{mLh}^{-1}$ on the $122^{\text {nd }}$ day of operation [54]. The performance of coupled system was studied with an initial atrazine concentration of $300 \mathrm{mg} \mathrm{L}^{-1}$ to yield a maximum removal efficiency of $93.0 \%$ for the coupled treatment system of UV-Fenton and biological method [169]. Malathion removal has been reported around 89.0\% in batch packed bioreactor [169]. In comparison, continuous packed bioreactor was also operated at various flow rates $\left(5-30 \mathrm{mLh}^{-1}\right)$ over a period of 75 days. The inlet loading rates and elimination capacities were reported in the range of 36-216 and 7.20-145.4 $\mathrm{mgL}^{-1} \mathrm{~d}^{-1}$, respectively with an average removal efficiency of more than $90.0 \%$ under steady state conditions [169].

Highly efficient colonization and contaminated soil exploration can be achieved using fungal populations due to their high branching and filamentous growth mode [60]. Highly filamentous fungal species (e.g., white-rot fungi) possess great advantages over most bacterial strains in terms of the wide range of hazardous compounds that they can oxidize [58]. Moreover, many fungal species are highly resistant to high concentrations of toxic compounds (e.g., pesticides) as compared to bacterial species [61]. As such, they are considered to be mighty biotechnological tools (many genetically modified fungal species have already been patented) in the field of biodegradation of soil pollutants [62].

\subsection{Types of Bioremediation}

\subsubsection{Bio-stimulation}

In bio-stimulation, vitamins, substrates, oxygen, and other required nutrients are added to stimulate the microbial activity for enhancing pesticide degradation. The addition of stimulating nutrients brings fresh carbon sources, which results in swift depletion of the available stocks of the main inorganic nutrients (e.g., phosphorus and nitrogen) [63]. Bio-stimulation has effectively been utilized for removing pesticides from the environment. The supplementary nutrients include organic/inorganic additives such as nitrate and phosphate. These supplementary nutrients could be essential for inducing enzyme formation and as co-metabolic substrates in the biodegradation pathway of pesticides [63]. To stimulate the microbe-assisted degradation of pesticides, a variety of water-soluble nutrients (e.g., $\mathrm{NH}_{3} \mathrm{NO}_{3}, \mathrm{NaNO}_{3}, \mathrm{KNO}_{3}, \mathrm{~K}_{2} \mathrm{HPO}_{4}$, and $\mathrm{MgNH}_{4} \mathrm{PO}_{4}$ ) are added to fertilizers [64].

As a general principle, the $\mathrm{N}: \mathrm{P}$ ratio is maintained between $5: 1$ and $10: 1$ for $1-5 \% \mathrm{~N}$ by weight of pesticide for the abatement of pesticides. These specific quantities might be inaccurate/insufficient for sites contaminated with different types of hazardous compounds [65]. Lima et al. [64] investigated the impact of soil inoculation with Pseudomonas sp. and bio-stimulation with citrate ( $\leq 4.8 \mathrm{mg} \mathrm{g}^{-1}$ of soil sample) on the microbe-assisted degradation of atrazine at very high concentrations (i.e., 20 to 200 times higher 
than the recommended dosage [RD]) (Table 4). Interestingly, at a very high atrazine concentration (i.e., 200 times higher than the $\mathrm{RD}$ value), the addition of citrate greatly boosted the removal efficiency from 79.0to $87.0 \%$ [64]. These authors noted that very high levels of atrazine (i.e., $62 \mathrm{mgg}^{-1}$ soil) can efficiently be removed by subsequent bio-stimulation and inoculation of soil with Pseudomonas sp.

\subsubsection{Bio-augmentation}

Bio-augmentation implies the addition of exogenous microbial populations with particular catabolic activities into a polluted site or a biological reactor to promote the biodegradation process. This might be an on-site or off-site operation that involves the addition of native microbes to contaminated sites for the elimination of hazardous pollutants $[16,66]$ and is widely recognized as an effective biotechnological approach for improving the degradation of pesticides in polluted water and soils [63]. Bio-augmentation has effectively been engaged for degrading a wide array of hazardous pollutants (e.g., $\mathrm{NH}_{3}, \mathrm{H}_{2} \mathrm{~S}$, petroleum products, and other organic contaminants) present in water and soils (Table 4) [67, 68]. The main advantages of the bio-augmentation are the addition of pre-grown microbial cultures to enhance microbial populations at a site to improve contaminant clean up and to reduce clean up time and cost.

A few case studies have been conducted on soil bio-augmentation for pesticide abatement (Table 4). Lima et al. [64] investigated the impact of inoculation of soil samples with Pseudomonas sp. on the microbe-assisted degradation of atrazine in a polluted soil (the atrazine concentration was in the range of 20-200 times higher than RD) (Table 4). It was reported that 99.0\% atrazine removal was achieved in the first 8 days (without citrate addition) aftersoil bio-augmentation for the soil having an atrazine concentration of 20 times higher than $\mathrm{RD}$ [64]. Under similar conditions, 79.0\% removal was obtained for the soil having an atrazine concentration as high as 200 times higher than RD. Similarly, Wang et al. [69] reported a high atrazine removal efficiency for Arthrobacter sp. based bio-augmentation of agricultural soil samples containing 400 $\mathrm{mg} \mathrm{kg}^{-1}$ of atrazine (Table 4). Bio-augmentation with Arthrobacter sp. displayed $90.0 \%$ and $70.0 \%$ removal of atrazine after the first three days for sterile and non-sterile soil samples, respectively.

Bio-augmentation of chloropyrifos using Alcaligenes faecalis has been conducted. Native cabbage plants were cultivated in the soil rich in chlorpyrifos at $100 \mathrm{mg} \mathrm{kg}^{-1}$ and bio-augmented with a strain of Alcaligenes faecalis. The study reported $100 \%$ chlorpyrifos removal after the first 12 days, whereas only $22.0 \%$ removal was attained in the control (Table 4) [70]. Similarly, Ahmad et al. [71] introduced Bacillus pumilus into soil samples rich in chlorpyrifos at $50 \mathrm{mg} \mathrm{kg}^{-1}$ and observed a $97.5 \%$ chlorpyrifos removal as compared to only $11.0 \%$ removal in the control (Table 4). Lakshmi et al. [72] also reported that the bio-augmented chlorpyrifos-rich soil samples at $50 \mathrm{mg} \mathrm{kg}^{-1}$ were individually treated with strains of Pseudomonas fluorescens and Bacillus subtilis. The average chlorpyrifos degradation was observed to be in the range of 85.0-92.0\% after the first 30 days for these bacterial strains as compared to only $34.0 \%$ chlorpyrifos removal in the control (Table 4).

The agricultural use of dichloro-diphenyl-trichloroethane (DDT) has been banned in the United States since 1973, although its residues/byproducts are still found to be persistent in soils around the globe. As a result, detoxification of such contaminated sites is a crucial task, and various bioremediation approaches are being actively used for this purpose. Recent investigations have elucidated that various fungal species can effectively remove DDT from the soils. This great potential of fungi was shown by Purnomo et al. [73]. The authors studied the capability of Gloeophyllum trabeum and Daedalae dickinsii to degrade DDT in polluted sterile/non-sterile soils. They observed that the introduction of these brown-rot fungi into an artificially contaminated sterile soil resulted in 41.0 and $15.0 \%$ degradation of DDT by $G$. trabeum and $D$. dickinsii, respectively. For non-sterile soil samples, G. trabeum and $D$. Dickinsii lowered the initial amount of DDT by approximately 43.0 and $32.0 \%$, respectively, when compared to the control (Table 4).

\subsection{Factors Influencing the Bioremediation of Pesticides Insoil}

The fate of pesticide molecules in soils is very complicated in interdependent physicochemical and biological processes. These complex interactions directly govern pesticide transport within the soil as well as their transfer from soil to air, food, and water. The chemical characteristics of pesticide molecules and soil characteristics govern the extent of the influence of the processes mentioned above.

\subsubsection{Structures of pesticides}

The structures of pesticides determine their physicochemical properties and inherent biodegradability. Pesticides are more susceptible to microbial attack and biodegradation if there are polar substituent on the phenyl ring, e.g., $-\mathrm{OH}$, $-\mathrm{COOH}$, and $-\mathrm{NH}_{2}$, whereas halogen or alkyl substituent tends to make the pesticide more resistant to biodegradation [5, 74]. Minor alteration in a structural substitute causes a drastic change in the susceptibility of a compound towards bio-transformation [22]. During the pesticide biodegradation process, the chemical structures of pesticides might drastically be changed by either oxidation or reduction of active functional groups, causing the breakdown of their complex structures into small molecules, such as carbon dioxide, nitrate, phosphate, ammonia, and water [75]. The 2D structures of selected pesticides are shown in Table 1. The toxicities of organochlorine pesticides are relatively lower as compared to organophosphate and carbamates pesticides. The toxicological properties are analogous to organochlorine pesticides that have similar structures, such as chlordane and heptachlor. The toxicity can vary depending on the position of the substituting chlorine in the molecule [76].

Chlorinated hydrocarbons (such as pentalene, dieldrin, and DDT) are unable to biodegrade because they are insoluble in water and have a high sorption affinity in soil [29]. In contrast, carbofuran and 2,4-dichlorophenoxyacetic acid (2,4-D) have different molecular structures and can be biodegraded in few days in field soils [54]. A minor difference in the position or nature of a substituent in the same class of pesticides can significantly influence the degradation rate [21, 54].

\subsubsection{Pesticide concentration}

The concentration of a pesticide in a soil $(\mathrm{P})$ is a crucial parameter for determining the biodegradation rate (i.e., $-\mathrm{d}[\mathrm{P}] / \mathrm{dt}$ ) in nature. 


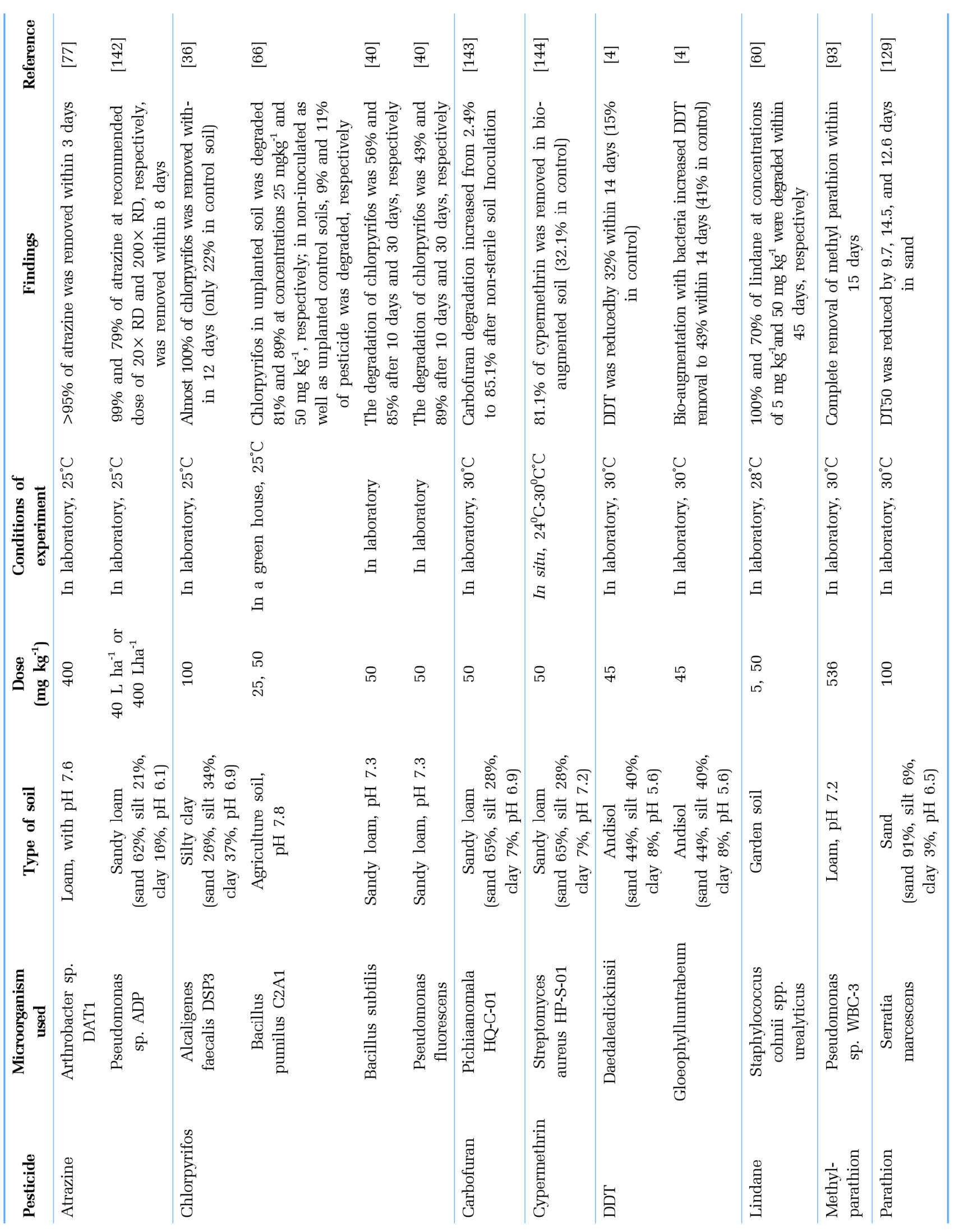


The degradation of numerous pesticides follows pseudo-first-order kinetics, where the biodegradation rate depends on the residual pesticide concentration [77]. The biodegradation rate decreases proportionally with the residual concentration of the pesticide (i.e., $\mathrm{d}[\mathrm{P}] / \mathrm{dt}=-k[\mathrm{P}])$, where $\mathrm{d}[\mathrm{P}] / \mathrm{dt}$ is the pesticide concentration gradient with respect to time, and $k$ is the biodegradation rate constant.

The half-life values of Inceptisol, Vertisol, and Ultimo are essentially independent of the initial pesticidedose, i.e., 10.1-31.0 d (1.0 $\mu \mathrm{gg}^{-1}$ soil) vs. $13.0-29.2 \mathrm{~d}\left(10.0 \mu \mathrm{g} \mathrm{kg}^{-1}\right.$ soil) [78]. In theory, the pesticide concentration for a 20-day half-life should decay to $0.2 \%$ of its initial concentration after 180 days. However, the biodegradation rate, $k$, is smaller at higher initial concentrations. The concentrations of pesticides (e.g., atrazine, carbofuran, cypermethrin, and chloropyrifos) used in experimental studies are given in Table 2. A half-life is the time required to reduce the amount of a given pesticide to a half level. This occurs as it dissipates or breaks down in the environment. After two half-lives, about $25 \%$ will remain. Several pesticides (e.g., DDT, HCH, endosulfan, BHC, and atrazine) belong to such ubiquitous compounds which persist in soil and sediments due to less bioavailability. Odukkathil and Vasudevan reported that the half life of less bio-available pesticides (e.g., DDT, HCH, endosulfan, BHC, and atrazine pesticides) ranges from 100 to $200 \mathrm{~d}$ [77]. Most of these residues are adsorbed on soil particles, and they are unavailable to the soil microbes for further degradation. In this review, an attempt has been made to present a brief idea on 'major limitations in pesticide biodegradation in soil' based ona few case studies.

\subsubsection{Soil types}

The soil characteristics (e.g., organic matter content, concentration of clay minerals, water content, and $\mathrm{pH}$ ) affect pesticide biodegradation in soil [78]. Soil plays an important role in microbe-assisted pesticide degradation in the environment. Soil particles can absorb the pesticides, thereby regulating bio-availability and influencing the persistence of pesticides [77]. The activity of microorganisms towards pesticide biodegradation can be influenced by soil characteristics such as clay content and type of organic matter. A number of variables (e.g., soil type, $\mathrm{pH}$, and clay content) can greatly influence the persistence of pesticidesunder field conditions including bifenthrin, chlorpyrifos, cypermethrin, fenvalerate, permethrin, and isofenphos. It has been further confirmed that the degradation rates of metalaxyl and propachlorin in soils were dependent on the soil conditions. The half-lives of metalaxyl and propachlor were 10 and 19 days for pasture soils, 36 and 2.6 days for arable soils, and 6.1 and 8.2 days for pine forest soils, respectively. Imidacloprid biodegradation and diazinon were faster in silty loam soil, followed by sandy loam and sandy soils [77].

\subsubsection{Moisture content}

Water is important for the motion and diffusion of pesticide molecules, and the presence of wateris vital for the microbe-assisted degradation of pesticides. Typically, the biodegradation of pesticides is observed to be very slow in dry (or negligible moisture content) soil samples. The transformation rate of pesticides is directly proportional to the moisture content in the soils [79]. Herbicides (e.g., atrazine and trifluralin) generally degrade at higher rates underanoxic conditions as compared to an oxygen-rich environment. DDT is fairly stable in aerobic soils but degrades very slowly with the formation of 2,3-dihydrodiol-DDT and 4-chlorobenzoic acid as metabolites in submerged soils [80].

\subsubsection{Temperature}

The molecular configurations of pesticide molecules govern the impact of temperature on their stability. Temperature impacts sorption of pesticides by changing their solubility and rate of hydrolysis in a soil sample in terms of salvation (G) and hydrolysis rate [81]. Growth of microorganisms and their activity are optimal in a well-defined physiological temperature range of $25-35^{\circ} \mathrm{C}$. Hence, pesticide degradation is optimal in a mesospheric temperature range of $25-40^{\circ} \mathrm{C}$ [82]. A temperature range of $15-40^{\circ} \mathrm{C}$ is thought to be suitable for the biodegradation of a pesticide by isolated pesticide-consuming bacterial strains [81, 83]. The optimal degradation temperature range of pesticides is shown in Table 2. Qingyan et al. [82] reported atrazine degradation at a temperature of $30^{\circ} \mathrm{C}$ and found $95.0 \%$ removal at a concentration of $500 \mathrm{mg} \mathrm{L}^{-1}$. Many studies for different pesticides, including carbofuran, chlorpyrifos, and DTT, showed that they were degraded in a temperature range of $25-30^{\circ} \mathrm{C}$, as shown in Table 2 [20, 83-85]. Temperature mainly affects the metabolism of bacterial species, such as Pseudomonas sp., Bacillus sp., and Alcaligenes sp., which perform well in a temperature range of $25-30^{\circ} \mathrm{C}$ [84-87].

\subsubsection{Soil acidity}

Soil acidity is an important parameter influencing the bioremediation of pesticides [88]. Essentially, the biodegradation of a pollutant molecule depends upon the particular enzymes produced by a microbial population. These enzymes operate in narrow $\mathrm{pH}$ ranges, as most bacterial species prefer an optimum soil $\mathrm{pH}$ range of 6.5-7.5, similar to their intracellular $\mathrm{pH}$. The $\mathrm{pH}$ of soil plays an important role in regulating pesticide adsorption and other biotic and abiotic degradation processes. It influences the adsorption tendency of a pesticide (on clay and organic matter), as well as the pesticide molecule's mobility, speciation, and bioavailability [89]. The effect of soil $\mathrm{pH}$ on the biodegradation of pesticide molecules largely depends upon their chemical susceptibility towards hydrolysis catalyzed by a base or an acid [19, 81]. Bacterial metabolism performs well at neutral $\mathrm{pH}$; hence, bioremediation studies are typically performed at $\mathrm{pH}$ 7.0. For example, Das et al. [85] conducted a study of atrazine degradation at $\mathrm{pH} 7.0$ by Pichia kudriavzevii and found an efficient removal of $94.3 \%$.

\subsubsection{Organic matter}

The organic matter present in soil can either decrease the pesticide biodegradation (through stimulation of pesticide sorption) or elevate microbial activity (through pesticide co-metabolism) [79]. The organic matter present in soil also influences biodegradation of pesticide molecules by supplying essential nutrients for cell growth and by governing their mobility via the adsorption/desorption process [90]. The bacteria-mediated biodegradation of organochlorine insecticides (e.g., benzenehexachloride [BHC], DDT, Methoxychlor, and heptachlor) was enhanced upon the introduction of organic carbon sources to flooded soils [91]. A minimum amount of organic matter (greater than 1\%) can secure an active population of autochthonous microbes capable of degrading pesticides. The introduction 
of wheat residue-derived biochar liberated micronutrients stimulated the growth of the microbial population for pesticide degradation in soil [92]. Organic matter can also be a co-substrate, which increases the microbial activity (production rate and biofilm formation) in a soil. Co-metabolism of microbes enables the biodegradation of pesticides present at relatively low concentrations; hence, microorganisms consume co-substrates to meet their carbon and energy needs. Soils enriched with organic matter contain a source of potential co-substrates, which can facilitate co-metabolic biodegradation of pesticides. The addition of a carbon-rich substrate to contaminated soil is used in bioremediation to stimulate the microbial activity and facilitate co-metabolism [93]. Tan et al. [94] reported that Bacillus sp. could degrade 98.5\% triazophos at 100 $\mathrm{mg} \mathrm{L}^{-1}$ from sewage sludge wastewater via co-metabolism when fed with nutrients, such as peptone, yeast extract, and glucose.

\subsection{Bioremediation Techniques: Developments and Applications}

\subsubsection{Isolation of pesticide-biodegrading microbes and their char-} acterization

The biodegradation rate of pesticides is typically very slow as compare to other reported techniques. To ensure sufficient degradation rate, specific microorganisms should be selected (Table 2). The isolation of naturally occurring effective microorganisms from a contaminated site is an important step in bioremediation. Therefore, many researchers have worked on the isolation, characterization, and biodegradation of pesticides [54]. Another researcher showed the degradation of $300 \mathrm{mg} \mathrm{L}^{-1}$ chloropyrifos using the Pseudomonas species isolated from an agricultural field and observed the removal efficiency greater than $91.0 \%$ (Table 5). Geed et al. [54] used isolated Bacillus sp. $\mathrm{S}_{4}$ for the degradation of Malathion at 300 mg L $\mathrm{L}^{-1}$ and achieved $90.0 \%$ removal in a continuous packed bed bioreactor (Table 5).

In recent years, a wide array of microbial strains has successfully been isolated that are capable of degrading hazardous compounds that were previously thought to be non-degradable, suggesting that microorganisms are rapidly evolving under the influence of rampant environmental contamination (Darwin's theory: the survival of the fittest species for the situation)to be able to degrade pesticides more effectively. Recently, the soil-derived microbial consortium capable of degrading a mixture of pesticides was analyzed using PCR-amplified 16S rRNA fragments [57]. The analysis detected 16S rRNA sequence types that represented organisms closely related to known pesticide-degrading bacteria (e.g.,Bacillus species) [95]. Several researchers have isolated the bacterial species and characterized for the effective pesticides degradation which are summarized in Table 2.

Isolation of atrazine-biodegrading species from herbicides containing wastewater was characterized by $16 \mathrm{~S}$ rRNA [96]. The thermal cycle operated at $94^{\circ} \mathrm{C}$ for 5 min for initial denaturation, followed by 35 cycles at $94^{\circ} \mathrm{C}$ for $30 \mathrm{~s}, 55^{\circ} \mathrm{C}$ for $30 \mathrm{~s}$, and $72^{\circ} \mathrm{C}$ for $30 \mathrm{~s}$, and a final incubation at $72^{\circ} \mathrm{C}$ for $10 \mathrm{~min}$. Yang et al. [97] isolated the novel bacterial Citricoccus sp. strain TT3 from the wastewater outfall of a pesticide factory (Table 5). Citricoccus sp. strain TT3 was analyzed using $16 \mathrm{~S}$ rRNA at an operating cycle consisting of preheating to $95^{\circ} \mathrm{C}$ for $2 \mathrm{~min}, 35$ cycles of denaturation at $95^{\circ} \mathrm{C}$ for $30 \mathrm{~s}$, annealing at $58^{\circ} \mathrm{C}$ for $30 \mathrm{~s}$, extension at $72^{\circ} \mathrm{C}$ for $90 \mathrm{~s}$, and a final extension for $5 \mathrm{~min}$ at $72^{\circ} \mathrm{C}$. Similarly, various microorganisms, such as Rhodococcus sp. strain, Bacillus sp., Acinetobacter, Stenotrophomonas sp., and Fischerella sp., were isolated and characterized by $16 \mathrm{~S}$ rRNA for pesticides such as DDT, endosulfane, lindane, parathion, malathion, and methyl parathion, as given in Table 5 [29, 98-102].

4.3.2. Cultivation in the laboratory to develop microbial populations Microorganisms capable of mineralizing a variety of pesticides under laboratory conditions have been isolated [5, 54]. These microorganisms were cultured in nutrient media as a co-substrate (i.e., glucose, nutrient broth, and yeast extract). The laboratory-grown microbes were commonly used for degradation experiments. Laboratory culturing of microorganisms is very important for efficient bioremediation in the field.

Isolation of an atrazine-degrading bacterial strain was done by procuring 25-mL of enriched sludge from anaerobic wastewater/municipal treatment provision in Israel [96] (Table 5). The sludge sample was incubated in a 250-mL flask under an oxygen-rich environment at $28^{\circ} \mathrm{C}$ in the presence of atrazine as the only source of nitrogen [96]. Stepwise incremental addition of atrazine was done from 7 to $30 \mathrm{mg} \mathrm{L}^{-1}$ over a period of 14 days. Three unique microbial colonies were observed via DNA sequencing analysis.

An isolated chloropyrifos-degrading species and contaminated soil samples were procured from an agricultural field in Varanasi, India (Table 5). The sampling site was utilized for extensive agricultural operations for several years and was greatly exposed to chlorpyrifos pesticide. Enriched bacterial isolate cultures were acquired from the contaminated soils by utilizing a suitable mineral salt medium (MSM). A chlorpyrifos stock solution at $25.0 \mathrm{mg} \mathrm{L}^{-1}$ was added into the MSM medium and left for a week-long incubation period. The control was based on a culture medium carrying only chlorpyrifos (e.g., without bacterial strains). The onset of turbidity can be an indicator of the growth of a bacterial population. Afterward, the vials that had a turbid appearance were placed on Luria Broth (LB) and minimal salt medium (MSM) agar culture plates holding chlorpyrifos populations; they were subsequently incubated at $30^{\circ} \mathrm{C}$ for 7 days.

An enrichment methodology was developed to isolate DDT- and endosulfane-degrading species using pesticide-contaminated (endosulfan and DDT) soils procured in large amounts from an insecticide facility in Cochin, India [98] (Table 5). Briefly, an enrichment medium was used to dissolve the contaminated soils along with the addition of an inoculums and minimalistic DDT as the only energy/carbon source with subsequent incubation. The enrichment process was repeated three times, and the resulting microbial culture was sequentially diluted and spread onto culture plates containing tryptic soy agar (TSA). Similarly, many researchers isolated microorganisms from pesticide-contaminated soils and wastewater using the cultivation methods in laboratories [101, 102].

4.3.3. Bench studies of microbes in a pesticide-contaminated soil The simplest strategy of bioremediation is improving the biodegradation performance of a microorganism through the addition of a 'specialist' organism. Microorganisms exhibit novel and high catabolic activity towards a target pollutant. The targeted pollutants are broken down into metabolites ina series of enzymatic reactions. 


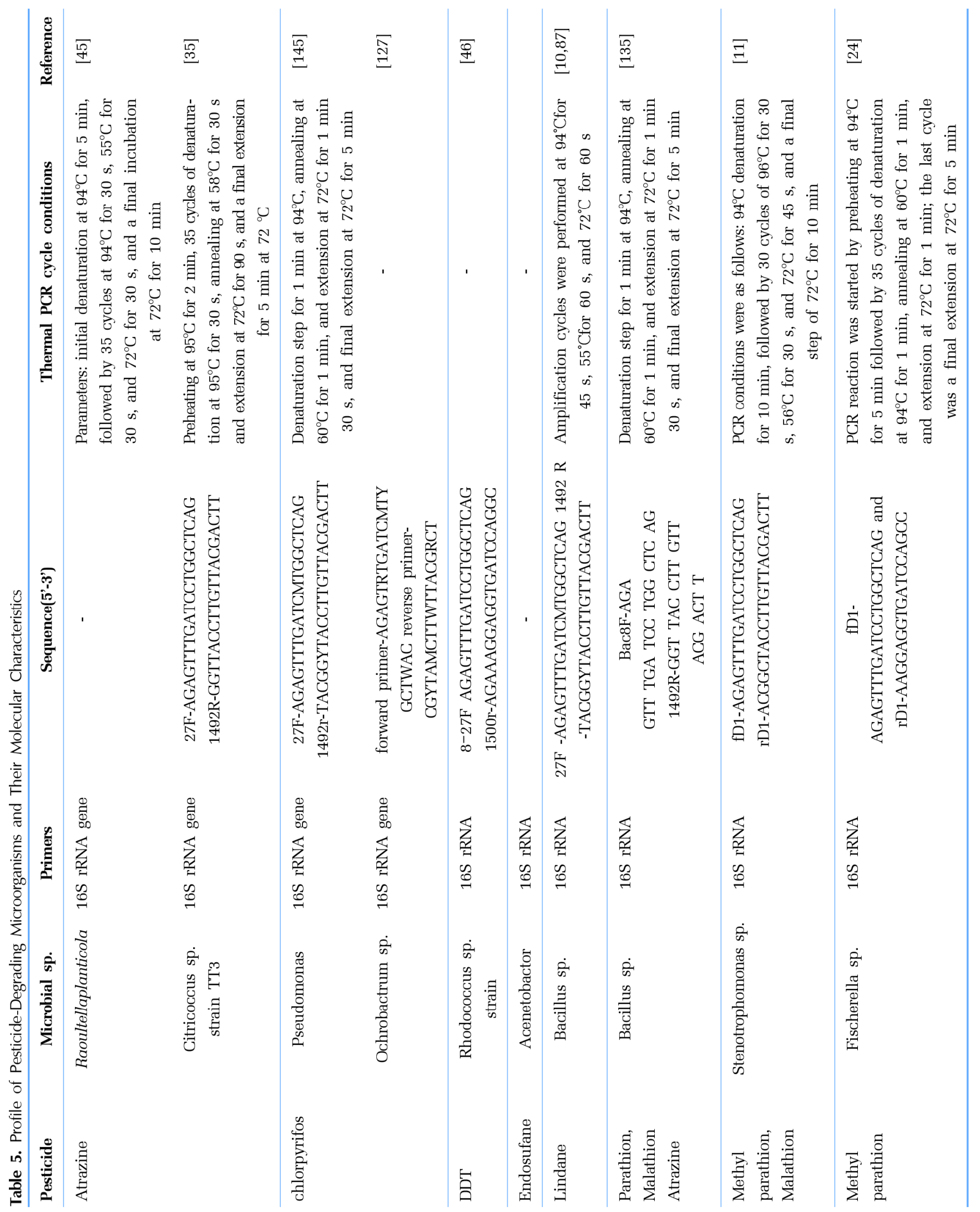


Many oxidase/reductase enzymes play important roles in pesticide breakdown. Batch-scale experiments have been performed by many researchers to understand the proper functioning of microbes. Bacterial colony growth was studied to ascertain the toxicity of a pollutant. Biodegradation of a pollutant was confirmed by using the available organic load and bacterial role. The progress of bioremediation and the production of metabolites were examined using various analysis methods, e.g., GC, FT-IR, and GC-MS. The pesticide metabolites were easily identified, and their toxicity was determined with respect to their parental compound [5, 54, 95].

Generally, acatabolic process occurs in microorganisms to breakdown pesticides. This may depend on what type of pesticide degradation is involved. The breakdown of any compound by microbial cells takes place through three unique processes, namely hydrolysis, reduction or oxidation, and addition. The hydrolysis of a pesticide molecule generally takes place in a water-rich environment. The oxidation or reduction of pesticide molecules is accompanied by a change in the pesticide's redox state [103]. The occurrence of either oxidation or reduction is governed by the presence of co-substrates in the environment. Finally, microbes add a new functional group to the pesticide molecule during the addition process. The strategy of addition is employed by microbes when the conditions prevailing in its surroundings are unfavorable for the other types of reactions. Although the addition process requires energy, the addition of a functional group elevates the susceptibility of the pollutant molecule towards biodegradation [96].

\subsection{Field Applications of Pesticide Bioremediation Techniques}

There are two basic treatment options depending on the site selected for pesticide treatment: in-situ and ex-situ bioremediation. In-situ bioremediation techniques involve on-site treatment of the hazardous material, whereas ex-situ approaches involve off-site treatment of toxic pollutants.

\subsubsection{In-situ techniques}

The in-situ technique involves the stimulation of microbial activity by adding microbes and nutrients and by optimizing factors associated with the environment at the polluted sites [104]. These techniques involve treating polluted substances at the selected site of the pollutant. Site excavation is not required; hence, there is little or no disruption to the soil structure. In-situ bioremediation involving the biological degradation of organic contaminants under naturally prevailing conditions can be described as a process whereby organic pollutants are biologically degraded to $\mathrm{CO}_{2}$, water, or other minimally toxic products under natural conditions. It is an economical, low-maintenance, environmentally benign, and sustainable undertaking for the detoxification of contaminated sites, as shown in Table 6. Seech et al. [104] reported a case study on the in-situ treatment of dieldrin in soil using the cycled DARAMEND treatment. Nearly 2,600 tons of dieldrin-contaminated soil was removed in the coastal areas of Florida, the United States in November2004. The total operation cost was estimated to be approximately 12.5 USD $\mathrm{yd}^{-3}$. The most practical in-situ methodologies and their salient features are as shown in Table 6.

\subsubsection{Ex-situ techniques}

$E X$-situ techniques involve excavating/removing the polluted soil from selected sites and transporting it to another site for treatment. $E X$-situ techniques are evaluated according to the cost of the treatment, type of pollutant, depth of pollution, geographical location, and degree of pollution. Methods include land farming and composting for off-site rehabilitation of polluted materials in specifically assigned locations. As a result of the added requirement of polluted soil excavation and transport, the operational cost of ex-situ approaches can be much higher than in-situ techniques, as shown in Table 6. Moreover, the biodegradation kinetics and consistency of the process outcomes for in-situ and ex-situ techniques is microbe dependent [105]. In-situ bioremediation is preferred over ex-situ for environmental rehabilitation of polluted soils and aqueous ecosystems [105]. The practicality of a specific biotechnological approach depends on multiple parameters, such as the condition of the contaminated site, native microbial populations, and the amount and toxicity of pesticide present. Ex-situ bioremediation techniques are shown in Table 6.

A case study on ex-situ treatment was carried out for initial concentrations of toxaphene, DDT, DDD, and DDE of 29, 94, 132, and $94 \mathrm{mg} \mathrm{kg}^{-1}$, respectively [104]. These authors reported that the remediation goals $(\geq 90 \%$ removal) were reached on various organochlorine pesticides (OCPs) in groundwater/saturated soils in the United States. The ex-situ bioremediation goals were reached in the treatment cell using 3-12 treatment cycles. The number of treatment cycles required to reach the remedial goal was primarily dependent on the initial concentrations of the target pesticides. Their results indicated that the initial concentrations of toxaphene, DDT, DDD, and DDE (i.e., 189, 81, 180, and $25 \mathrm{mg} \mathrm{kg}^{-1}$, respectively) were reduced to $10,9,52$, and $6 \mathrm{mg} \mathrm{kg}^{-1}$, respectively. These changes correspond to removal and destruction efficiencies (RDEs) of 95.0, 89.0, 71.0, and 76.0\%, respectively. The treatment cost per ton varied in relation to their initial concentration, ranging from 29-63 USD $\mathrm{t}^{-1}$, and average treatment cost would be $\sim 55 \mathrm{USDt}^{-1}$ for 4,500 tons of contaminated soil.

\subsection{Hybrid Bioreactors}

Pesticide treatment in bioreactors has the benefit of continuous monitoring of waste processing under controlled conditions. Bioreactor technology can be customized in wide-ranging arrangements to maximize microbial degradation [63]. Yadav et al. [5] studied the degradation of chlorpyrifos through Pseudomonas sp. in batch and continuous reactors using polyurethane foam as the packing media. They optimized the process parameters for maximizing the removal efficiency of chlorpyrifos through batch experiments and determined the following optimal parameters: $\mathrm{pH} 7.5$, a temperature of $37^{\circ} \mathrm{C}$, a DO of $5.5 \mathrm{mg} \mathrm{L}^{-1}$, and a chlorpyrifos concentration of $500 \mathrm{mg} \mathrm{L}^{-1}$. Further, the bioreactor operating under continuous mode was run at different flow rates from $10-40 \mathrm{mLh}^{-1}$ and displayed $91.0 \%$ removal of chlorpyrifos at steady state. Geed et al. [54] employed the integrated aerobic treatment plant (IATP) to treat synthetic wastewater containing atrazine, Malathion, and parathion using isolated Bacillus sp. (Consortia) from an agricultural field. The maximum COD removal of synthetic wastewater in IATP was greater than $90.0 \%$.

Multiple types of bioreactors are available all around the globe including continuous, batch, sequential, membrane, airlift, and 


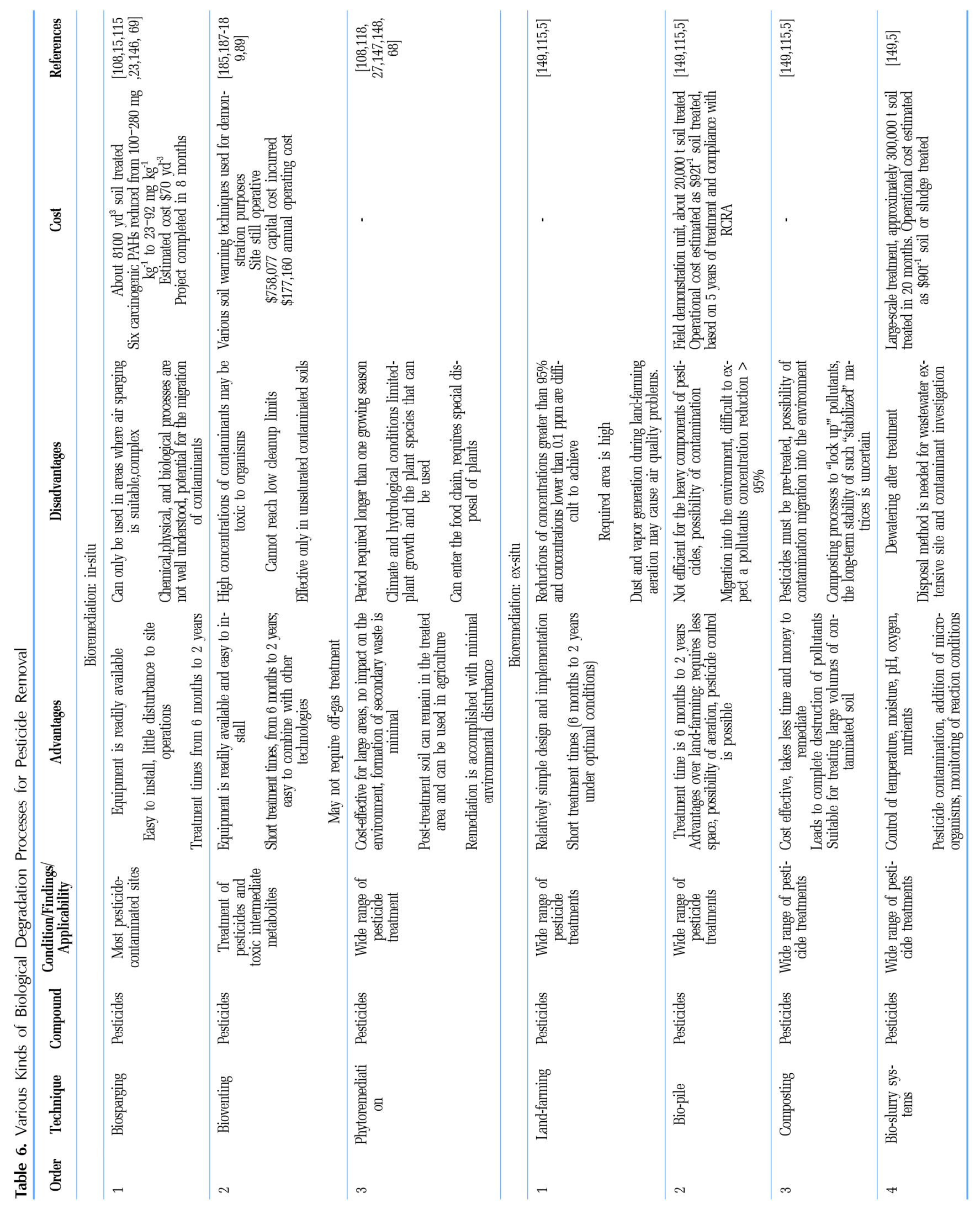


fluidized bed, biofilm, and hybrid systems [106, 107]. Although such bioreactors have the great advantage of control, they suffer from the drawbacks of high operation/capital costs along with the requirement of polluted site excavation. Other off-site biodegradation techniques include land farming, composting, and bio-piles. These methods are found to have various disadvantages, such as large space requirement, extended treatment duration, mass transfer problems, and restricted bio-availability of contaminants [108]. Table S1 shows the different types of bioreactors used for bioremediation.

Hybrid processes that are an effective combination of multiple treatment methodologies have been proposed. Some may have the ability to effectively remove organic pollutants. The synergistic effects can effectively be utilized to enhance the abatement of pesticides through the combination of multiple processes. For example, the presence of activated carbon can elevate the biodegradability of previously highly recalcitrant pesticide molecules via adsorption [109].

Interestingly, combining suspended biomass with biofilm has been proposed as an innovative strategy for potential enhancements in pesticide biodegradation due to biodiversity expansion in the treatment system. The utilization of bio-filtering setups consisting of bio-films grown on fixed beds has intensively been investigated with the main emphasis on porous media biofiltration processes (e.g., sand filters) [110]. The retention time plays a crucial role in controlling the suspended biomass culture-based conventional systems for organic pollutants. Therefore, the best performance can be anticipated using biofilm processes at low loadings (resulting in a more diverse bacterial colony). Luo et al. [35] investigated the short-term removal rates of pesticides during 24-h batch experiments through acclimatized as well as non-acclimatized biomasses supported on a sponge. A continuous bench-scale moving bed biofilm reactor (MBBR) was also set up for a long-term assessment of 100 days to remove selected organic pollutants. In their subsequent study, Luo et al. [35] compared the removal of pollutants using a conventional membrane bioreactor (MBR) and a hybrid MBBR-MBR system. The observed results showed that the hybrid MBBR-MBR system was better for the abatement of recalcitrant pesticides.

The fouling of membranes was greatly lowered in the hybrid reactor due to the variation in the soluble species of the microorganisms and the extracellular polymeric materials. Additionally, an improvement in the pesticide removal was attained with a novel configuration of a plant built on an up-flow anaerobic sludge blanket (UASB) reactor integrated with a hybrid aerobic MBR at room temperature with alow hydraulic retention time (HRT) [109]. Interestingly, significant removal of aqueous pesticide molecules was observed due to the synergistic effect of the combination of cross-linked enzyme aggregates of laccase (CLEA-laccase) and microfiltration membranes [111]. The sequential treatment steps can also be used to treat pesticide-rich wastewater through aerobic or anaerobic processes [19, 112].

The levels of pesticides in water have increased due to their excessive use in the modern agricultural domain. Choosing a suitable water treatment method for pesticide removal depends on the type of pesticide and the efficacy of the treatment process. Both single-treatment and hybrid methods are thoroughly described and critically discussed [5, 35, 54, 108-110]. The use of hybrid removal techniques offers the potential opportunities to develop innovative options. Furthermore, the decentralization of water treatment was also discussed as a means to improve effluent water quality at lower prices. Many affordable techniques such as activated sludge and adsorption by agricultural adsorbents showed high efficacy in treating high levels of different pesticides.

\subsection{Economic Cost and Sustainability of Bioremediation}

Bioremediation technology is considered to be a highly economic approach compared to conventional pesticide abatement technologies (approximate savings of 65.0-85.0 \%). For instance, the incineration of contaminated soil costs approximately 250-500 USD $\mathrm{t}^{-1}$, whereas biotechnological approaches are estimated to require an operational cost of 40-70 USD $t^{-1}$ [113]. The estimated cost of microbe-assisted treatment of contaminated soil is approximately one-third cheaper than that of conventional soil remediation methods [114]. Bio-treatment typical costs of incineration and landfill disposal are 50-130, 300-1,000, and 200-300 USDm ${ }^{-3}$, respectively [106, 115].

Various biotechnological approaches have been applied for microbe-assisted degradation of pesticides in contaminated soils (e.g., on-site subsurface techniques, land-farming/engineered oil pile methods, and fully blended soil slurry reactors for ex-situ abatement of contaminated excavated soils). The aim of bioremediation is to stimulate the optimum process environment to catalyze the growth of appropriate microorganisms and use them to decompose pollutants. Modern biological treatment systems have successfully been applied for the abatement of a wide range of pesticides.

However, many studies have shown that bioremediation approaches are kinetically slow and have not been able to lower pesticide concentrations to environmentally accepted values. Due to its poor performance historywith the rash of "quick-fix" methodologies (but without proper field trials and validation), potential users have become more unwilling to adopt biological treatment technologies [116]. The costs of analyses and sampling increases substantially in the case of non-homogeneous process conditions which resulting in highly elevated operational costs. Advent of modern biotechnological tools can help accelerate bioremediation operation and provide higher process reliability [17, 30, 117]. Timeframe may range from 5-25 years for natural processes, 0.5-3 years for in-situ sub-surface processes, 1-18 months for soil composting processes, 1-12 months for land-farming and slurry phase systems, and 15 days for accelerated slurry phase systems [118].

\section{Conclusions and Future Work}

The physicochemical processes involved in the removal of pesticides from various environmental matrixes were described at the beginning of this review to provide a clear contrast with the subsequently discussed biological approaches. The physicochemical approaches are often energy intensive and costly in nature for practical implementation for pesticide treatment. Some physicochemical processes often require the application of chemical compounds to worsen environmental pollution issues and to amplify the overall operational costs. Among all available methods, bio- 
remediation methods are the most promising, eco-friendly, and inexpensive approaches for the effective degradation of various pesticides present in the environment. Various microorganisms have been employed as biological agents for the degradation of pesticides into either non-toxic or less toxic byproducts. Bioremediation approaches combined with conventional techniques can be used to detoxify and remove hazardous pesticides in heavily contaminated soils with $>95 \%$ removal efficiency and incidental benefits.

Although bioremediation has proven to be a promising tool for the degradation/detoxification of pesticides, its sustainability in the field is still questionable. It would be difficult to achieve complete degradation/detoxification of pesticides in nature since the biochemical pathways of microbial species are strongly dependent on the physicochemical properties of soils. Therefore, further research is imperative for a better understanding of degradation pathways by microbes and their interactions with soils having various contaminants and different environmental conditions.

Bioremediation has a critical limitation for pesticide abatement in terms of maintaining optimum conditions for the growth of microbial populations. The rate of pesticide degradation is also very slow and time-consuming. Pesticide degradation, the exploration of specific microbes for specific pesticides, optimization of the process parameters, development of a highly efficient bioreactor, and verification of natural, easily available, and highly porous packing media should be further investigated.

Advanced biotechnological/microbiological tools and genetic engineering can help provide swift advancements in the area of pesticide bioremediation by developing robust and highly adaptable microbial strains and by improving the treatment facilities/technologies that already exist. Using these tools, genes may be targeted that are responsible for biodegradation, and further studies can be done to obtain better results. Further collaborations between genetic engineers, biochemists, environmental engineers, and microbiologists are required to overcome the various hurdles remaining in the present bioremediation methodologies and to further improve the research and development directions as recommended.

\section{Acknowledgments}

The authors gratefully acknowledge the Ministry of Human Resource Development, India (MHRD, India) for providing financial support and the Indian Institute of Technology (BHU) for providing laboratory space to conduct research work. KHK acknowledges support made by a grant from the National Research Foundation of Korea (NRF) funded by the Ministry of Science, ICT \& Future Planning (No. 2016R1E1A1A01940995). This work was also supported by the "Cooperative Research Program for Agriculture Science \& Technology Development (Project No. PJ014297)" Rural Development Administration, Republic of Korea.

\section{Author Contributions}

B.S.G (Post Doctoral Fellow), S.R.G (Ph.D), K.V. (Ph.D) have written this review and S.S.L. (Professor), K.H.K. (Distinguish Professor), S.K.K. (Professor), M.V. (Professor), critically review the paper on various aspect while P.C. (Scientist), R.S.S. (Professor), B.N.R. (Professor) and K.H.K. (Distinguish Professor) have supervised the PDF and Ph.D Scholars.

\section{References}

1. Li R, Wang, J, Li, S. Eleftherohorinos IG. Biodegradation of omethoate by Bacillus sp. YB-10: optimization of culture conditions and degradation characteristics. Environ. Eng. Res. 2021;26(4):1-9.

2. Ahari M, Foltz NT, Mazéas L, Sorption of chlorophenols on geotextile of the geosynthetic clay liners. Environ. Eng. Res. 2020;25(2):163-170.

3. Agency CI. The World Fact book 2016, Central Intelligence Agency (CIA). 2017.

4. Helbling DE. Bioremediation of pesticide-contaminated water resources: the challenge of low concentrations. Curr. Opin. Biotech. 2015;33:142-148.

5. Yadav IC, Devi NL, Syed JH, et al. Current status of persistent organic pesticides residues in air, water, and soil, and their possible effect on neighboring countries: a comprehensive review of India. Sci. Total Environ. 2015;511:123-137.

6. Kim SK. Trophic transfer of organochlorine pesticides through food-chain in coastal marine ecosystem. Environ. Eng. Res. 2020;25(1):43-51.

7. Sharpe RM, Irvine DS. How strong is the evidence of a link between environmental chemicals and adverse effects on human reproductive health. BMJ. 2004;328(7437):447-451.

8. Ormad MP, Miguel N, Claver A, Matesanz JM, Ovelleiro JL. Pesticides removal in the process of drinking water production. Chemosphere 2008;71(1):97-106.

9. Plakas KV, Karabelas AJ. Removal of pesticides from water by NF and RO membranes-A review. Desalination 2012;287: 255-265.

10. Mandal A, Singh N. Optimization of atrazine and imidacloprid removal from water using biochars: Designing single or multi-staged batch adsorption systems. Int. J. Environ. Res. Public Health 2017;220(3):637-645.

11. Mandal K, Singh B, Jariyal M, Gupta VK. Microbial degradation of fipronil by Bacillus thuringiensis. Ecotoxicol. Environ. Saf. 2013;93:87-92.

12. Aresta A, Marzano CN, Lopane C, et al. Analytical investigations on the lindane bioremediation capability of the demosponge Hymeniacidon pelvis. Mar. Pollut. Bull. 2015;90(1-2):143-149.

13. Saez JM, Aparicio JD, Amoroso MJ, Benimeli CS. Effect of the acclimation of a Streptomyces consortium on lindane biodegradation by free and immobilized cells. Process Biochem. 2015;50(11):1923-1933.

14. Gupta M, Mathur S, Sharma TK, et al. A study on metabolic prowess of Pseudomonas sp. RPT 52 to degrade imidacloprid, endosulfan and coragen. J. Hazard. Mater. 2016;301:250-258.

15. Vikrant K, Giri BS, Raza N, et al. Recent advancements in bioremediation of dye: current status and challenges. Bioresour. Technol. 2018a;253:355-367. 
16. Perelo LW. In situ and bioremediation of organic pollutants in aquatic sediments. J. Hazard. Mater. 2010;177(1-3):81-89.

17. Giri BS, Goswami M, Pandey RA, Kim KH. Kinetics and biofiltration of dimethyl sulfide emitted from P\&P industry. Biochem. Eng. J. 2015;102:108-114.

18. Hussaini SZ, Shaker M, Iqbal MA. Isolation of bacterial for degradation of selected pesticides. Adv. Biores. 2013;4(3):82-85.

19. Liu C, Xu X, Fan J. Accelerated anaerobic dechlorination of DDT in slurry with HydragricAcrisols using citric acid and anthraquinone-2, 6-disulfonate (AQDS). Int. J. Environ. Sci. 2015;38:87-94

20. Liu J, Tan L, Wang J, Wang Z, Ni H, Li L. Complete biodegradation of chlorpyrifos by engineered Pseudomonas putida cells expressing surface-immobilized laccases. Chemosphere 2016;157: 200-207.

21. Geed SR, Prasad S, Kureel MK, Singh RS, Rai BN. Biodegradation of wastewater in alternating aerobic-anoxic lab scale pilot plant by Alcaligenes sp. S3 isolated from agricultural field. J. Environ. Manage. 2018a;214:408-415.

22. Geed SR, Kureel MK, Prasad S, Singh RS, Rai BN. Novel study on biodegradation of malathion and investigation of mass transfer correlation using alginate beads immobilized Bacillus sp. S4 in bioreactor. J. Environ. Chem. Eng. 2018b;6(2):3444-3450.

23. Wagschal K, Franqui-Espiet D, Lee CC,Kibblewhite-Accinelli RE, Robertson GH, Wong DW. Genetic and biochemical characterization of an $\alpha$-L-arabinofuranosidase isolated from a compost starter mixture. Enzyme Microb. Technol. 2007;40(4):747-753.

24. Manolov I. Lecture 5: Soil ferility and organic fertilizers in organic farming [Doctoral dissertation]. Agricultural University of Tirana; 2014.

25. Saxton KE, Rawls WJ. Soil water characteristic estimates by texture and organic matter for hydrologic solutions. Soil Sci. Soc. Am. J. 2006;70(5);1569-1578.

26. Szulejko JE, Kumar P, Deep A, Kim KH. Global warming projections to 2100 using simple $\mathrm{CO}_{2}$ greenhouse gas modeling and comments on $\mathrm{CO}_{2}$ climate sensitivity factor. Atmos. Pollut. Res. 2017;8(1):136-140.

27. Watson SL. Assessing the impacts of unrestricted pesticide use in small-scale Agriculture on water quality and associated human health and ecological implications in an indigenous village in rural Panam [dissertation]. Tampa: Univ. South Florida; 2014.

28. Jess S, Kildea S, Moody A, Rennick G, Murchie AK, Cooke LR. European Union policy on pesticides: implications for agriculture in Ireland. Pest Manag. Sci. 2014;70(11):1646-1654.

29. Geed SR, Raj A, Kureel MK, et al. Removal of Atrazine by coupling Fenton reaction with bioreactor in series.Indian J. Exp. Biol. 2017a;55(7):498-505.

30. Sonwani RK, Giri BS, Das T, Singh RS, Rai BN. Biodegradation of fluorene by neoteric LDPE immobilized Pseudomonas pseudoalcaligenes NRSS3 in a packed bed bioreactor and analysis of external mass transfer correlation. Process Biochem. 2019;77: 106-112.

31. Popp J, Pető K, Nagy J. Pesticide productivity and food security. A review. Agron. Sustain. Dev. 2013;33(1):243-255.

32. De Gaetano Y, Hubert J, Mohamadou A, et al. Removal of pesticides from wastewater by ion-pair Centrifugal Partition
Extraction using betaine-derived ionic liquids as extractants. Chem. Eng. J. 2016;285:596-604

33. Li R, Yang C, Chen H, Zeng G, Yu G, Guo J. Removal of triazophos pesticide from wastewater with Fenton reagent. J. Hazard. Mater. 2009;167(1-3):1028-1032.

34. MoussaviG, Alahabadi A, Yaghmaeian K, Eskandari M. Preparation, characterization and adsorption potential of the $\mathrm{NH} 4 \mathrm{Cl}$-induced activated carbon for the removal of amoxicillin antibiotic from water. Chem. Eng. J. 2013;217:119-128.

35. Luo Y, Guo W, Ngo HH, et al. Removal and fate of micro-pollutants in a sponge-based moving bed bioreactor. Bioresour. Technol. 2014;159:311-319.

36. Gupta S, Gajbhiye VT. Effect of concentration, moisture and soil type on the dissipation of flufenacet from soil. Chemosphere 2002a;47:901-906.

37. Kuster M, de Alda MJL, Hernando MD, Petrovic M, Martín-Alonso J, Barceló D. Analysis and occurrence of pharmaceuticals, estrogens, progestogens and polar pesticides in sewage treatment plant effluents, river water and drinking water in the Llobregat river basin (Barcelona, Spain). J. Hydrol. 2008;358(1-2):112-123.

38. European Parliament and Council, (EPC), Directive 2000/60/EC of the European Parliament and of the Council of 23 October 2000. Establishing a Framework for Community Action in the Field of Water Policy. EFT L 327 of 22.12.2000. European Parliament and Council. 2000.

39. Gupta B, Priya T, Mishra BK, Augmentation of the coagulation activity of alum using a porous bio-flocculant for the remediation of trihalomethanes-generating hydrophobic natural organic matter. Environ. Eng. Res. 2021;26(3):200234.

40. Hedegaard MJ, Albrechtsen HJ. Microbial pesticide removal in rapid sand filters for drinking water treatment-potential and kinetics. Water Res. 2014;48:71-81.

41. Saini R, Kumar P. Simultaneous removal of methyl parathion and chlorpyrifos pesticides from model wastewater using coagulation/flocculation: Central composite design. J. Environ. Chem. Eng. 2016;4(1):673-680.

42. Golbaz S, Jafari AJ, Rafiee M, Kalantary RR. Separate and simultaneous removal of phenol, chromium, and cyanide from aqueous solution by coagulation/precipitation: Mechanisms and theory. Chem. Eng. J. 2014;253:251-257.

43. Zhao Y, Taylor JS. Incorporation of osmotic pressure in an integrated incremental model for predicting RO or NF permeate concentration. Desalination 2005;174(2):145-159.

44. Mehta R, Brahmbhatt H, Saha NK, Bhattacharya A. Removal of substituted phenyl urea pesticides by reverse osmosis membranes: Laboratory scale study for field water application. Desalination 2015;358:69-75.

45. Lopes MP, Matos CT, Pereira VJ, et al. Production of drinking water using a multi-barrier approach integrating nanofiltration: A pilot scale study. Sep. Purif. Technol. 2013;119:112-122.

46. Madsen HT, Søgaard EG. Applicability and modelling of nanofiltration and reverse osmosis for remediation of groundwater polluted with pesticides and pesticide transformation products. Sep. Purif. Technol. 2014;125:111-119.

47. Gorenflo A, Velázquez-Padrón D, Frimmel FH. Nanofiltration of a German groundwater of high hardness and NOM content: 
performance and costs. Desalination 2003;151(3):253-265.

48. Pan J. Atrazine degradation in the ultraviolet (UV) irradiation/hydrogen peroxide $\left(\mathrm{H}_{2} \mathrm{O}_{2}\right)$ treatment. Adv. Mat. Res. 2013;726:1823-1826.

49. Esplugas S, Contreras S, Ollis DF. Engineering aspects of the integration of chemical and biological oxidation: simple mechanistic models for the oxidation treatment. J. Environ. Chem. Eng. 2004;130(9):967-974.

50. Kang N, Lee DS, Yoon J. Kinetic modeling of Fenton oxidation of phenol and mono-chlorophenols. Chemosphere 2002;47(9): 915-924.

51. Deng X, Huang J, Rozelle S, Uchida E. Cultivated land conversion and potential agricultural productivity in China. Land Use Policy 2006;23(4):372-384.

52. Seeger EM, Kuschk P, Fazekas H, Grathwohl P, Kaestner M. Bioremediation of benzene-, MTBE-and ammonia-contaminated groundwater with pilot-scale constructed wetlands. Environ. Pollut. 2011;159(12):3769-3776.

53. Singh K, Giri BS, Sahi A, et al. Biofiltration of xylene using wood charcoal as the biofilter media under transient and high loading conditions. Bioresour. Technol. 2017;242:351-358.

54. Geed SR, Kureel MK, Giri BS, Singh RS, Rai BN. Performance evaluation of Malathion biodegradation in batch and continuous packed bed bioreactor (PBBR). Bioresour. Technol. 2017b;227: 56-65.

55. Anjum R, Rahman M, Masood F, Malik A. Bioremediation of pesticides from soil and wastewater. In: Environmental Protection Strategies for Sustainable Development. Springer, Dordrecht; 2012. p. 295-328.

56. Karpouzas DG, Singh BK. Microbial degradation of organo-phosphorus xeno-biotics: metabolic pathways and molecular basis. Adv. Microb. Physiol. 2006;51:119-225.

57. Geed SR, Shrirame BS, Singh RS, Rai BN. Assessment of pesticides removal using two-stage Integrated Aerobic Treatment Plant (IATP) by Bacillus sp. isolated from agricultural field. Bioresour. Technol. 2017c;242:45-54.

58. Pointing S. Feasibility of bioremediation by white-rot fungi. Appl. Microbiol. Biotechnol. 2001;57(1-2):20-33.

59. Reddy CA, Mathew Z. Bioremediation potential of white rot fungi. In British Mycological Society Symposium Series. 2001;23:52-78.

60. Verdin A, Sahraoui ALH, Durand R. Degradation of benzo [a] pyrene by mitosporic fungi and extracellular oxidative enzymes. Int. Biodeterior. Biodegradation 2004;53(2):65-70.

61. Gadd GM, Gadd GM. (Eds.). Fungi in bioremediation (No. 23). Cambridge University Press. 2001.

62. Steffen KT, Schubert S, Tuomela M, Hatakka A, Hofrichter M. Enhancement of bioconversion of high-molecular mass polycyclic aromatic hydrocarbons in contaminated non-sterile soil by litter-decomposing fungi. Biodegradation 2007;18(3):359-369.

63. Plangklang P, Reungsang A. Bioaugmentation of carbofuran by Burkholderiacepacia PCL3 in a bio-slurry phase sequencing batch reactor. Process Biochem. 2010;45(2):230-238.

64. Lima D, Viana P, André S, et al. Evaluating a bioremediation tool for atrazine contaminated soils in open soil microcosms: the effectiveness of bioaugmentation and biostimulation approaches. Chemosphere 2009;74(2):187-192.
65. Yang L, Chen S, Hu M, Hao W, Geng P, Zhang Y. Biodegradation of carbofuran by Pichia anomala strain HQ-C-01 and its application for bioremediation of contaminated soils. Biol. Fert. Soils 2011;47(8):917-923.

66. Head MA., Oleszkiewicz JA. Bioaugmentation for nitrification at cold temperatures. Water Res. 2004;38(3):523-530.

67. Park D, Lee DS, Kim YM, Park JM. Bioaugmentation of cyanide-degrading microorganisms in a full-scale cokes wastewater treatment facility. Bioresour. Technol. 2008;99(6):2092-2096.

68. Xu G, Zheng W, Li Y, Wang S, Zhang J, Yan Y. Biodegradation of chlorpyrifos and 3, 5, 6-trichloro-2-pyridinol by a newly isolated Paracoccus sp. strain TRP. Int. Biodeterior. Biodegradation 2008;62(1):51-56.

69. Wang Q, Xie S, Hu R. Bioaugmentation with Arthrobacter sp. strain DAT1 for remediation of heavily atrazine-contaminated soil. Int. Biodeterior. Biodegradation 2013;77:63-67.

70. Yang L, Zhao YH, Zhang BX, Yang CH, Zhang X. Isolation and characterization of a chlorpyrifos and 3, 5, 6-trichloro-2-pyridinol degrading bacterium. FEMS Microbiol. Lett. 2005;251(1):67-73.

71. Ahmad F, Iqbal S, Anwar S, et al. Enhanced remediation of chlorpyrifos from soil using ryegrass (Loliummultiflorum) and chlorpyrifos-degrading bacterium Bacillus pumilus C2A1. J. Hazard. Mater. 2012;237:110-115.

72. Lakshmi CV, Kumar M, Khanna S. Biotransformation of chlorpyrifos and bioremediation of contaminated soil. Int. Biodeterior. Biodegradation 2008;62(2):204-209.

73. Purnomo AS, Mori T, Takagi K, Kondo R. Bioremediation of DDT contaminated soil using brown-rot fungi. Int. Biodeterior. Biodegradation 2011;65(5):691-695.

74. Geed SR, Kureel MK, Shukla AK, Singh RS, Rai BN. Biodegradation of malathion and evaluation of kinetic parameters using three bacterial species. Resource-Efficient Technologies 2016;2:S3-S11.

75. Porto ALM, Melgar GZ, Kasemodel MC, Nitschke M. Biodegradation of pesticides. In: Pesticides in the Modern World-Pesticides Use and Management. Intech. Open; 2011. p. 407-438.

76. Singh DK. Pesticide chemistry and toxicology. Sharjah: Bentham Science Publishers; 2012.

77. Pal R, Chakrabarti K, Chakraborty A, Chowdhury A. Degradation and effects of pesticides on soil microbiological parameters-A review. Int. J. Agric. 2006;1(33):240-258.

78. Gupta S, Gajbhiye V. Effect of concentration, moisture and soil type on the dissipation of flufenacet from soil. Chemosphere 2002a;47:901-906.

79. Chowdhury A, Pradhan S, Saha M, Sanyal N. Impact of pesticides on soil microbiological parameters and possible bioremediation strategies. Indian J. Microbiol. 2008;48(1):114-127.

80. Alvarez M, Calle A, Tamayo J, Lechuga LM, Abad A, Montoya A. Development of nanomechanical biosensors for detection of the pesticide DDT. Biosens. Bioelectron. 2003;18(5-6):649-653.

81. Singh R, Jhorar RK, Van Dam JC, Feddes RA. Distributed ecohydrological modelling to evaluate irrigation system performance in Sirsa district, India II: Impact of viable water management scenarios. J. Hydrol. 2006b;329(3-4):714-723.

82. Qingyan LI, Ying LI, Xikun ZHU, Baoli CAI. Isolation and charac- 
terization of atrazine-degrading Arthrobacter sp. AD26 and use of this strain in bioremediation of contaminated soil. Int. J. Environ. Sci. 2008;20(10):1226-1230.

83. Plangklang P, Reungsang A. Bioaugmentation of carbofuran residues in soil using Burkholderiacepacia PCL3 adsorbed on agricultural residues. Int. Biodeterior. Biodegradation 2009; 63(4):515-522.

84. Kong L, Zhu S, Zhu L, et al. Biodegradation of organochlorine pesticide endosulfan by bacterial strain Alcaligenes faecalis JBW4. Int. J. Environ. Sci. 2013;25(11):2257-2264.

85. Das N. Removal of atrazine from the aqueous environment using immobilized Pichia kudriavzevii Atz-EN-01 by two different methods. Int. Biodeterior. Biodegradation 2015;104:53-58.

86. Cycoń M, Wójcik M, Piotrowska-Seget Z. Biodegradation of the organophosphorus insecticide diazinon by Serratia sp. and Pseudomonas sp. and their use in bioremediation of contaminated soil. Chemosphere 2009;76(4):494-501.

87. Mandal K. Singh B, Jariyal M, Gupta VK. Bioremediation of fipronil by a Bacillus firmus isolate from soil. Chemosphere 2014;101:55-60.

88. Arshad M, Saleem M, Hussain S. Perspectives of bacterial ACC deaminase in phytoremediation. Trends Biotechnol. 2007;25(8): 356-362.

89. Chaney RL. Toxic element accumulation in soils and crops: protecting soil fertility and agricultural food-chains. In: Inorganic contaminants in the vadose zone. Springer, Berlin, Heidelberg. 1989; p. 140-158.

90. Fellman JB, Hood E, Spencer RG. Fluorescence spectroscopy opens new windows into dissolved organic matter dynamics in freshwater ecosystems: A review. Limnol. Oceanogr. 2010; 55(6):2452-2462.

91. Matsui T, Omasa K, Horie T. The difference in sterility due to high temperatures during the flowering period among japonica-rice varieties. Plant Prod. Sci.2001;4:90-93.

92. Kookana RS, Sarmah AK, Van Zwieten L, Krull E, Singh B. Biochar application to soil: agronomic and environmental benefits and unintended consequences. Adv. Agron. Academic Press.2011;112:103-143.

93. Banwart SA, Noellemeyer E, Milne, E. Soil carbon: Science, management and policy for multiple benefits. CABI. 2014;71.

94. Tan H, Cao Y, Tang T, Qian K, Chen WL, Li J. Biodegradation and chiral stability of fipronil in aerobic and flooded paddy soils. Sci. Total Environ. 2008;407(1):428-437.

95. Srivastva N, Singh RS, Upadhyay SN, Dubey SK. Degradation kinetics and metabolites in continuous biodegradation of isoprene. Bioresour. Technol. 2016;206:275-278.

96. Swissa N, Nitzan Y, Langzam Y, Cahan R. Atrazine biodegradation by a monoculture of Raoultellaplanticola isolated from a herbicides wastewater treatment facility. Int. Biodeterior. Biodegradation 2014;92:6-11.

97. Yang X, Wei H, Zhu C, Geng B. Biodegradation of atrazine by the novel Citricoccus sp. strain TT3. Ecotoxicol. Environ. Saf. 2018;147:144-150.

98. Bajaj A, Mayilraj S, Mudiam MKR, Patel DK, Manickam N. Isolation and functional analysis of a glycolipid producing Rhodococcus sp. strain IITR03 with potential for degradation of 1, 1, 1-trichloro-2, 2-bis (4-chlorophenyl) ethane (DDT).
Bioresour. Technol. 2014;167:398-406.

99. Thangadurai P, Suresh S. Biodegradation of endosulfan by soil bacterial cultures. Inter. Biodeter. Biodegradation 2014;94:38-47.

100. Deng S, Chen Y, Wang D, et al. Rapid biodegradation of organophosphorus pesticides by Stenotrophomonas sp. G1. J. Hazard. Mater. 2015;297:17-24.

101. Pannu R, Kumar D. Process optimization of $\gamma$-Hexachlorocyclohexane degradation using three novel Bacillus sp. strains. Biocatal. Agric. Biotechnol. 2017;11:97-107.

102. Tiwari B, Chakraborty S, Srivastava AK, Mishra AK. Biodegradation and rapid removal of methyl parathion by the paddy field cyanobacterium Fischerella sp. Algal Res. 2017;25:285-296.

103. Scott C, Begley C, Taylor M, et al. Free-Enzyme Bioremediation of Pesticides: A case study for the enzymatic remediation of organophosphorous insecticide residues.ACSSymp. Ser. Am. Chem. Soc. 2011;1075:155-174.

104. Seech A, Bolanos, K, Hill D, Molin J. In situ bioremediation of pesticides in soil and groundwater. Remed. J. 2008;19(1): 87-98.

105. Jorgensen KS. In situ bioremediation. Adv. Appl. Microbiol. 2007;61:285-305.

106. Asadi A, Zinatizadeh AAL, Sumathi S. Simultaneous removal of carbon and nutrients from an industrial estate wastewater in a single up-flow aerobic/anoxic sludge bed (UAASB) bioreactor. Water Res. 2012;46(15):4587-4598.

107. Neoh CH, Noor ZZ, Mutamim NSA, Lim CK. Green technology in wastewater treatment technologies: integration of membrane bioreactor with various wastewater treatment systems. Chem. Eng. J. 2016;283:582-594.

108. Vidali M. Bioremediation. An overview. Pure Appl. Chem. 2001;73(7):1163-1172.

109. Alvarino T, Suarez S, Garrido M, Lema JM, Omil F. A UASB reactor coupled to a hybrid aerobic MBR as innovative plant configuration to enhance the removal of organic micro-pollutants. Chemosphere 2016;144:452-458.

110. Casas ME, Bester K. Can those organic micro-pollutants that are recalcitrant in activated sludge treatment be removed from wastewater by biofilm reactors (slow sand filters). Sci. Total Environ. 2015;506:315-322.

111. Nguyen LN, Hai FI, Price WE, et al. Degradation of a broad spectrum of trace organic contaminants by an enzymatic membrane reactor: complementary role of membrane retention and enzymatic degradation. Int. Biodeterior. Biodegradation 2015;99:115-122.

112. Cesar A, Ros M. A long-term study of nitrate, nitrite and pesticide removal from groundwater: A two-stage biological process. Int. Biodeterior. Biodegradation 2013;82:117-123.

113. Eykelbosh A. Short-and long-term health impacts of marine and terrestrial oil spills. Vancouver Coastal Health. 2014.

114. Onwurah INE, Ogugua, VN, Onyike, NB, Ochonogor AE, Otitoju OF. Crude oil spills in the environment, effects and some innovative clean-up biotechnologies. Int. J. Environ. Res. 2007;1(4):307-320.

115. Vu B, Chen M, Crawford R, Ivanova E. Bacterial extracellular polysaccharides involved in biofilm formation. Molecules 2009;14(7):2535-2554. 
116. Srinivasan U. US bioremediation markets. Frost and Sullivan research report. 2003;1-300.

117. Hoff RZ. Bioremediation: an overview of its development and use for oil spill cleanup. Mar. Pollut. Bull. 1993;26(9):476-481.

118. Ward OP. The industrial sustainability of bioremediation processes. J. Ind. Microbiol. Biot. 2004;31(1):1-4.

119. Pavel LV, Gavrilescu M. Overview of ex situ decontamination techniques for soil cleanup. Environ. Eng. Manag. J. 2008;7(6): 815-834.

120. Plangklang P, Reungsang A. Bioaugmentation of carbofuran residues in soil by Burkholderiacepacia PCL3: A small-scale field study. Int. Biodeterior. Biodegradation 2011;65(6): 902-905.

121. Qu J, Xu Y, Ai GM, Liu Y, Liu ZP. Novel Chryseobacterium sp. PYR2 degrades various organochlorine pesticides (OCPs) and achieves enhancing removal and complete degradation of DDT in highly contaminated soil. J. Environ. Manage. 2015;161:350-357.

122. Rao RP, Kaliwal BB. Monocrotophos induced dysfunction on estrous cycle and follicular development in mice. Ind. Health 2002;40(3):237-244.

123. Reina AC, Miralles-Cuevas S, López JC, Pérez JS. Pyrimethanil degradation by photo-Fenton process: Influence of iron and irradiance level on treatment cost. Sci.Total Environ. 2017;605:230-237.

124. Rigas F, Dritsa V, Marchant R, Papadopoulou K, Avramides EJ Hatzianestis I. Biodegradation of lindane by Pleurotusostreatus via central composite design. Environ. Int. 2005;31(2):191-196.

125. Rodrigues GN, Alvarenga N, Vacondio $\mathrm{B}$, et al. Biotransformation of methyl parathion by marine-derived fungi isolated from ascidian Didemnumligulum. Biocatal. Agric. Biotechnol. 2016;7:24-30.

126. Kmellár B, Fodor P, Pareja L, et al. Validation and uncertainty study of a comprehensive list of 160 pesticide residues in multi-class vegetables by liquid chromatography-tandem mass spectrometry. J. Chromatogr. A 2008;1215(1-2):37-50.

127. Saiyed H, Dewan A, Bhatnagar V, Shenoy U, Shenoy R, Rajmohan H, Lakkad B. Effect of endosulfan on male reproductive development. Environ. Health Perspect. 2003; 111(16):1958-1962.

128. Sari AA, Tachibana S, Itoh K. Determination of co-metabolism for 1, 1, 1-trichloro-2, 2-bis (4-chlorophenyl) ethane (DDT) degradation with enzymes from Trametes versicolor U97. J. Biosci. Bioeng. 2012;114(2):176-181.

129. Lewis WH, Elvin-Lewis MP. Medical botany: plants affecting human health. John Wiley \& Sons. 2003.

131. Singh B, Kaur J, Singh K. Biodegradation of malathion by Brevibacillus sp. strain KB2 and Bacillus cereus strain PU. World J. Microbiol. Biotechnol. 2012;28(3):1133-1141.

132. Singh P, Saini HS, Raj M. Rhamnolipid mediated enhanced degradation of chlorpyrifos by bacterial consortium in soil-water system. Ecotoxicol. Environ. Saf. 2016;134:156-162.

133. Song YF, Xiao LU, Ren FS. Variability of pesticide residues in vegetables from the marketplaces in Jinan city. Agr. Sci. China 2011;10(10):1646-1652.

134. Steffen KT, Schubert S, Tuomela M, Hatakka A, Hofrichter
M. Enhancement of bioconversion of high-molecular mass polycyclic aromatic hydrocarbons in contaminated non-sterile soil by litter-decomposing fungi. Biodegradation 2007;18(3): 359-369.

135. Susarla S, Medina VF, McCutcheon SC. Phytoremediation: an ecological solution to organic chemical contamination. Ecol. Eng. 2002;18(5):647-658.

136. Castelo-Grande T, Barbosa D. Soil decontamination by supercritical extraction. Electron. J. Environ. Agric. Food Chem. 2003;2(2):1-6.

137. Colborn T, VomSaal FS, Soto AM. Developmental effects of endocrine-disrupting chemicals in wildlife and humans. Environ. Health Perspect. 1993;101(5):378-384.

138. Drufovka K, Danevčič T, Trebše P, Stopar D. Microorganisms trigger chemical degradation of diazinon. Int. Biodeterior. Biodegradation 2008;62(3):293-296.

139. Tingle CCD, Rother JA, Dewhurst CF, Lauer S, King WJ. Health and environmental effects of fipronil. Briefing paper for Pesticides Action Network, UK. 2000.

140. Tingle CC, Rother JA, Dewhurst CF, Lauer S, King WJ. Fipronil: environmental fate, ecotoxicology, and human health concerns. Springer, New York, NY. Rev. Environ. Contam. T. 2003;1-66.

141. Tiwari B, Chakraborty S, Srivastava AK, Mishra AK. Biodegradation and rapid removal of methyl parathion by the paddy field cyanobacterium Fischerella sp. Algal Res.2017;25:285-296.

142. Uzunhisarcikli M, Kalender Y, Dirican K, Kalender S, Ogutcu A, Buyukkomurcu F. Acute, subacute and subchronic administration of methyl parathion-induced testicular damage in male rats and protective role of vitamins C and E. Pestic. Biochem. Phys. 2007;87(2):115-122.

143. Grewal KK, Sandhu GS, Kaur R, Brar RS, SandhuHS. Toxic impacts of cypermethrin on behavior and histology of certain tissues of albino rats. Toxicol. Int.2010;17(2):94-98.

144. Guillén-Jiménez FDM, Cristiani-Urbina E, Cancino-Díaz JC, Flores-Moreno JL, Barragán-Huerta BE. Lindane biodegradation by the Fusarium verticillioides AT-100 strain, isolated from Agave tequilana leaves: kinetic study and identification of metabolites. Int. Biodeterior. Biodegradation 2012;74:36-47.

145. Van der Bruggen B, Vandecasteele C. Removal of pollutants from surface water and groundwater by nanofiltration: overview of possible applications in the drinking water industry. Environ. Pollut. 2003;122(3):435-445.

146. Verma AK, Dash RR, Bhunia P. A review on chemical coagulation/flocculation technologies for removal of colour from textile wastewaters. J. Environ. Manage. 2012;93(1):154-168.

147. Wang L, Chi XQ, Zhang JJ, Sun DL, Zhou NY. Bioaugmentation of a methyl parathion contaminated soil with Pseudomonas sp. strain WBC-3. Int. Biodeterior. Biodegradation 2014;87: 116-121.

148. Wu Y, Bressette D, Carrell JA, et al. Tumor necrosis factor (TNF) receptor superfamily member TACI is a high affinity receptor for TNF family members APRIL and BLyS. J. Biol. Chem. 2000;275(45):35478-35485.

149. Xia H, Ma X. Phytoremediation of ethion by water hyacinth 
(Eichhornia crassipes) from water. Bioresour. Technol.2006; 97(8):1050-1054.

150. Yadav M, Srivastva N, Singh RS, Upadhyay SN, Dubey SK. Biodegradation of chlorpyrifos by Pseudomonas sp. in a continuous packed bed bioreactor. Bioresour. Technol. 2014;165:265-269.

151. Yahaya GO. Separation of volatile organic compounds (BTEX) from aqueous solutions by a composite organophilic hollow fiber membrane-based pervaporation process. J. Membr. Sci. 2008;319(1-2):82-90.

152. Yan C, Barlow S, Wang Z, et al. Non-fullerene acceptors for organic solar cells. Nat. Rev. Mater. 2018;3:18003.

153. Yang T, Zhang Q, Chen YD, Tao X, Xu CY, Chen X. A spatial assessment of hydrologic alteration caused by dam construction in the middle and lower Yellow River, China. Hydrol. Process. 2008;22(18):3829-3843.

154. Yu JJ. Removal of organophosphate pesticides from wastewater by supercritical carbon dioxide extraction. Water Res.2002; 36(4):1095-1101.

155. Yuguo Z, Zhao W, Xiaolong C. Citric acid production from the mash of dried sweet potato with its dregs by Aspergillus niger in an external-loop airlift bioreactor. Process Biochem. 1999;35(3-4):237-242.

156. Zhang H, Xiao R, Wang D, He G, Shao S, Zhang J, Zhong $\mathrm{Z}$. Biomass fast pyrolysis in a fluidized bed reactor under $\mathrm{N}_{2}, \mathrm{CO}_{2}, \mathrm{CO}, \mathrm{CH}_{4}$ and $\mathrm{H}_{2}$ atmospheres. Bioresour. Technol. 2011;102(5):4258-4264.

157. Zhao G, Huang Q, Rong X, Cai P, Liang W, Dai K. Biodegradation of methyl parathion in the presence of goethite: The effect of Pseudomonas sp. Z1 adhesion. Int. Biodeterior. Biodegradation 2014;86:294-299.

158. Mudliar SN, Giri BS, Padoley K, Satpute D, Dixit R, Bhatt P, Pandey RA, Juwarkar AA, Vaidya AN. Bioreactors for treatment of VOCs and odours-a review. J. Environ. Manage. 2010;91(5):1039-1054.

159. Giri BS, Juwarkar A, Mudliar SN, Pandey RA. Treatment of waste gas containing low concentration of dimethyl sulphide in a high performancebiotrickling filter. Indian J. Exp.
Biol.2013;51(11):1018-1023.

160. Abhilash PC, Singh N. Pesticide use and application: an Indian scenario. J. Hazard. Mater.2009;165(1-3):1-12.

161. Kumar M, Prasad D, Giri BS, Singh RS. Temperature control of fermentation bioreactor for ethanol production using IMC-PID controller. Bio. Rep. 2019;22:e00319.

162. Geed SR, Prasad S, Kureel MK, Singh RS, Rai BN. Biodegradation of wastewater in alternating aerobic-anoxic lab scale pilot plant by Alcaligenes sp. S3 isolated from agricultural field. J. Environ. Manage.2018;214:408-415.

163. Pannu R, Kumar D. Process optimization of $\gamma$ Hexachlorocyclohexane degradationusing three novel Bacillus sp. strains. Biocatal. Agric. Biotechnol. 2017;11:97-107.

164. Kumar D, Jaswal S. Chopra S. Co-degradation study of lindane and chlorpyrifos by novel bacteria. Int. J. Environ. Waste Manag. 2017;20(4): 283-299.

165. Kumar D. Kumar A. Sharma J. Degradation study of lindane by novelstrainsKocuria sp. DAB-1Y and Staphylococcus sp. DAB-1W. Bioresour. Bioprocess. 2016;3:53.

166. Kumar D. Pannu R. Perspectives of lindane $(\gamma$ -hexachlorocyclohexane) biodegradation from the environment: a review. Bioresour. Bioprocess. 2018;5:29.

167. Kumar D. Biodegradation of $\gamma$-Hexachlorocyclohexane byBurkholderiasp.IPL04. Biocatal. Agric. Biotechnol. 2018;16: 331-339.

168. Pannu R. Kumar D. Biodegradation study of $\gamma$ -hexachlorocyclohexane using selected bacteria isolated from agricultural soil. Afr. J. Microbiol. Res. 2014;8(36):3335-3346.

169. Odukkathil G. Vasudevan N. Toxicity and bioremediation of pesticides in agricultural soil. Rev. Environ. Sci. Biotechnol. 2013;12:421-444.

170. Geed SR, Raj A, Kureel MK, et al. Singh RS. Studies on removal of Atrazine by coupling Fenton reaction with bioreactor in series. Indian J. Exp. Biol. 2017d;55:55(7):498-505.

171. Bruggen BV. Microfiltration, ultra-filtration, nanofiltration, reverse osmosis, and forward osmosis. In the book Fundamental Modelling of Membrane Systems Membrane and Process Performance. 2018. p. 25-70. 